\title{
To cleave or not to cleave in XL-MS?
}

\section{Supplementary Material}

B. Steigenberger ${ }^{1,2^{*}}$, P. Albanese ${ }^{1,2^{*}}$, A.J.R. Heck ${ }^{1,2}$, R.A. Scheltema ${ }^{1,2 \$}$

1. Biomolecular Mass Spectrometry and Proteomics, Bijvoet Center for Biomolecular Research and Utrecht Institute for Pharmaceutical Sciences, Utrecht University, Padualaan 8, 3584 CH Utrecht, The Netherlands.

2. Netherlands Proteomics Centre, Padualaan 8, 3584 CH Utrecht, The Netherlands.

* Equal contribution

\$ Address reprint requests to R.A. Scheltema, Padualaan 8, $3584 \mathrm{CH}$ Utrecht, The Netherlands, r.a.scheltema@uu.nl 


\section{Table S1}

To write this review, we manually collected a total of 296 articles published in the time-frame of 2009 to 2019 [1-296]. As filter criteria, we applied the following rules:

1. The paper represents the genesis of a new cross-linking reagent or is an application to a real biological system;

2. The paper was published in the set time-frame;

3. The detected crosslinked peptide pairs were used to interpret the results (e.g. formaldehyde crosslinked proteins intended to stabilize the complex were not included).

The whole collection is provided as separate excel sheet with pubmed identifier and extra columns containing meta-information like the used reagent, data acquisition platform, and many others.

In case we missed a publication, we sincerely apologize. This was not on purpose, but due to the overwhelming task of digging through a decade worth of published results. The body of work this library however already constitutes a fantastic collection of structural biology papers uncovering protein structure information in fine detail in collaboration with other structural biology techniques like cryoEM. We wish to acknowledge this work with references in this supplementary table, as there simply is no space to do so in the main text. We would also like to encourage the reader to have a look at some of these papers at the very least. 


\section{References}

1. Krauth, F., Ihling, C.H., Rüttinger, H.H., Sinz, A.: Heterobifunctional isotope-labeled amine-reactive photo-cross-linker for structural investigation of proteins by matrixassisted laser desorption/ionization tandem time-of-flight and electrospray ionization LTQ-Orbitrap mass spectrometry. Rapid Commun. Mass Spectrom. 23, 2811-2818 (2009). doi:10.1002/rcm.4188

2. Zhang, H., Tang, X., Munske, G.R., Tolic, N., Anderson, G.A., Bruce, J.E.: Identification of protein-protein interactions and topologies in living cells with chemical cross-linking and mass spectrometry. Mol. Cell Proteomics. 8, 409-420 (2009). doi:10.1074/mcp.M800232-MCP200

3. Dahlberg, C.L., Nguyen, E.Z., Goodlett, D., Kimelman, D.: Interactions between Casein kinase Iepsilon (CKIepsilon) and two substrates from disparate signaling pathways reveal mechanisms for substrate-kinase specificity. PLoS One. 4, e4766 (2009). doi:10.1371/journal.pone.0004766

4. Kolstoe, S.E., Ridha, B.H., Bellotti, V., Wang, N., Robinson, C. V, Crutch, S.J., Keir, G., Kukkastenvehmas, R., Gallimore, J.R., Hutchinson, W.L., Hawkins, P.N., Wood, S.P., Rossor, M.N., Pepys, M.B.: Molecular dissection of Alzheimer's disease neuropathology by depletion of serum amyloid P component. Proc. Natl. Acad. Sci. U.S.A. 106, 76197623 (2009). doi:10.1073/pnas.0902640106

5. Petrotchenko, E. V, Xiao, K., Cable, J., Chen, Y., Dokholyan, N. V, Borchers, C.H.: BiPS, a photocleavable, isotopically coded, fluorescent cross-linker for structural proteomics. Mol. Cell Proteomics. 8, 273-286 (2009). doi:10.1074/mcp.M800265-MCP200

6. Manolaridis, I., Mumtsidu, E., Konarev, P., Makhov, A.M., Fullerton, S.W., Sinz, A., Kalkhof, S., McGeehan, J.E., Cary, P.D., Griffith, J.D., Svergun, D., Kneale, G.G., Tucker, P.A.: Structural and biophysical characterization of the proteins interacting with the herpes simplex virus 1 origin of replication. J. Biol. Chem. 284, 16343-16353 (2009). doi:10.1074/jbc.M806134200

7. Kalkhof, S., Haehn, S., Paulsson, M., Smyth, N., Meiler, J., Sinz, A.: Computational modeling of laminin N-terminal domains using sparse distance constraints from disulfide bonds and chemical cross-linking. Proteins. 78, 3409-3427 (2010). doi:10.1002/prot.22848

8. Liu, F., Goshe, M.B.: Combinatorial electrostatic collision-induced dissociative chemical cross-linking reagents for probing protein surface topology. Anal. Chem. 82, 6215-6223 (2010). doi:10.1021/ac101030w 
9. Yang, L., Tang, X., Weisbrod, C.R., Munske, G.R., Eng, J.K., von Haller, P.D., Kaiser, N.K., Bruce, J.E.: A photocleavable and mass spectrometry identifiable cross-linker for protein interaction studies. Anal. Chem. 82, 3556-3566 (2010). doi:10.1021/ac902615g

10. Müller, M.Q., Dreiocker, F., Ihling, C.H., Schäfer, M., Sinz, A.: Fragmentation behavior of a thiourea-based reagent for protein structure analysis by collision-induced dissociative chemical cross-linking. J Mass Spectrom. 45, 880-891 (2010). doi:10.1002/jms.1775

11. Dreiocker, F., Müller, M.Q., Sinz, A., Schäfer, M.: Collision-induced dissociative chemical cross-linking reagent for protein structure characterization: applied Edman chemistry in the gas phase. J. Mass Spectrom. 45, 178-89 (2010). doi:10.1002/jms.1702

12. Nagao, R., Suzuki, T., Okumura, A., Niikura, A., Iwai, M., Dohmae, N., Tomo, T., Shen, J.-R.R., Ikeuchi, M., Enami, I.: Topological analysis of the extrinsic PsbO, PsbP and PsbQ proteins in a green algal PSII complex by cross-linking with a water-soluble carbodiimide. Plant Cell Physiol. 51, 718-727 (2010). doi:10.1093/pcp/pcq042

13. Trnka, M.J., Burlingame, A.L.: Topographic Studies of the GroEL-GroES Chaperonin Complex by Chemical Cross-linking Using Diformyl Ethynylbenzene THE POWER OF HIGH RESOLUTION ELECTRON TRANSFER DISSOCIATION FOR DETERMINATION OF BOTH PEPTIDE SEQUENCES AND THEIR ATTACHMENT SITES* $\square$ S Downl. (2010). doi:10.1074/mcp.M110.003764

14. Gomes, A.F., Gozzo, F.C.: Chemical cross-linking with a diazirine photoactivatable crosslinker investigated by MALDI- and ESI-MS/MS. J. Mass Spectrom. 45, 892-899 (2010)

15. Müller, M.Q., Dreiocker, F., Ihling, C.H., Schäfer, M., Sinz, A.: Cleavable cross-linker for protein structure analysis: Reliable identification of cross-linking products by tandem MS. Anal. Chem. 82, 6958-6968 (2010). doi:10.1021/ac101241t

16. Chen, Z.A., Jawhari, A., Fischer, L., Buchen, C., Tahir, S., Kamenski, T., Rasmussen, M., Lariviere, L., Bukowski-Wills, J.C., Nilges, M., Cramer, P., Rappsilber, J.: Architecture of the RNA polymerase II-TFIIF complex revealed by cross-linking and mass spectrometry. EMBO J. 29, 717-726 (2010). doi:10.1038/emboj.2009.401

17. Blattner, C., Jennebach, S., Herzog, F., Mayer, A., Cheung, A.C.M., Witte, G., Lorenzen, K., Hopfner, K.-P., Heck, A.J.R., Aebersold, R., Cramer, P.: Molecular basis of Rrn3regulated RNA polymerase I initiation and cell growth. Genes Dev. 25, 2093-2105 (2011). doi:10.1101/gad.17363311

18. Kolenko, P., Rozbeský, D., Vaněk, O., Kopecký, V., Hofbauerová, K., Novák, P., Pompach, P., Hašek, J., Skálová, T., Bezouška, K., Dohnálek, J.: Molecular architecture of mouse activating NKR-P1 receptors. J. Struct. Biol. 175, 434-441 (2011). doi:10.1016/j.jsb.2011.05.001 
19. Gold, M.G., Stengel, F., Nygren, P.J., Weisbrod, C.R., Bruce, J.E., Robinson, C. V, Barford, D., Scott, J.D.: Architecture and dynamics of an A-kinase anchoring protein 79 (AKAP79) signaling complex. Proc. Natl. Acad. Sci. U.S.A. 108, 6426-6431 (2011). doi:10.1073/pnas.1014400108

20. Janganan, T.K., Bavro, V.N., Zhang, L., Matak-Vinkovic, D., Barrera, N.P., VenienBryan, C., Robinson, C. V, Borges-Walmsley, M.I., Walmsley, A.R.: Evidence for the assembly of a bacterial tripartite multidrug pump with a stoichiometry of 3:6:3. J. Biol. Chem. 286, 26900-26912 (2011). doi:10.1074/jbc.M111.246595

21. Braun, N., Zacharias, M., Peschek, J., Kastenmüller, A., Zou, J., Hanzlik, M., Haslbeck, M., Rappsilber, J., Buchner, J., Weinkauf, S.: Multiple molecular architectures of the eye lens chaperone $\alpha B$-crystallin elucidated by a triple hybrid approach. Proc. Natl. Acad. Sci. U.S.A. 108, 20491-20496 (2011). doi:10.1073/pnas.1111014108

22. Zheng, C., Yang, L., Hoopmann, M.R., Eng, J.K., Tang, X., Weisbrod, C.R., Bruce, J.E.: Cross-linking Measurements of In Vivo Protein Complex Topologies. Mol. Cell. Proteomics. 10, M110.006841 (2011). doi:10.1074/mcp.M110.006841

23. Petrotchenko, E. V., Serpa, J.J., Borchers, C.H.: An Isotopically Coded CID-cleavable Biotinylated Cross-linker for Structural Proteomics. Mol. Cell. Proteomics. 10, M110.001420 (2011). doi:10.1074/mcp.M110.001420

24. Kao, A., Chiu, C., Vellucci, D., Yang, Y., Patel, V.R., Guan, S., Randall, A., Baldi, P., Rychnovsky, S.D., Huang, L.: Development of a novel cross-linking strategy for fast and accurate identification of cross-linked peptides of protein complexes. Mol. Cell. proteomics. 10, M110.002212 (2011). doi:10.1074/mcp.M110.002212

25. Lipstein, N., Schaks, S., Dimova, K., Kalkhof, S., Ihling, C., Kölbel, K., Ashery, U., Rhee, J., Brose, N., Sinz, A., Jahn, O.: Nonconserved $\mathrm{Ca}(2+) /$ calmodulin binding sites in Munc13s differentially control synaptic short-term plasticity. Mol. Cell. Biol. 32, 46284641 (2012). doi:10.1128/MCB.00933-12

26. Liu, F., Wu, C., Sweedler, J. V, Goshe, M.B.: An enhanced protein crosslink identification strategy using CID-cleavable chemical crosslinkers and LC/MS(n) analysis. Proteomics. 12, 401-405 (2012). doi:10.1002/pmic.201100352

27. Nadeau, O.W., Lane, L.A., Xu, D., Sage, J., Priddy, T.S., Artigues, A., Villar, M.T., Yang, Q., Robinson, C. V, Zhang, Y., Carlson, G.M.: Structure and location of the regulatory $\beta$ subunits in the $(\alpha \beta \gamma \delta) 4$ phosphorylase kinase complex. J. Biol. Chem. 287, 36651-36661 (2012). doi:10.1074/jbc.M112.412874

28. Ciferri, C., Lander, G.C., Maiolica, A., Herzog, F., Aebersold, R., Nogales, E.: Molecular architecture of human polycomb repressive complex 2. Elife. 1, e00005 (2012). doi:10.7554/eLife.00005 
29. Jennebach, S., Herzog, F., Aebersold, R., Cramer, P.: Crosslinking-MS analysis reveals RNA polymerase I domain architecture and basis of rRNA cleavage. Nucleic Acids Res. 40, 5591-5601 (2012). doi:10.1093/nar/gks220

30. Haladová, K., Mrázek, H., Ječmen, T., Halada, P., Man, P., Novák, P., Chmelík, J., Obšil, T., Šlc, M.: The combination of hydrogen/deuterium exchange or chemical cross-linking

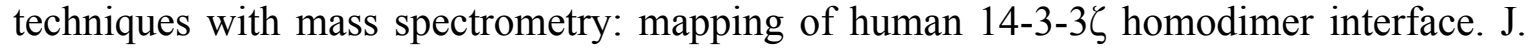
Struct. Biol. 179, 10-17 (2012). doi:10.1016/j.jsb.2012.04.016

31. Robinson, P.J.J., Bushnell, D.A., Trnka, M.J., Burlingame, A.L., Kornberg, R.D.: Structure of the mediator head module bound to the carboxy-terminal domain of RNA polymerase II. Proc. Natl. Acad. Sci. U.S.A. 109, 17931-17935 (2012). doi:10.1073/pnas.1215241109

32. Wu, C.-C., Herzog, F., Jennebach, S., Lin, Y.-C., Pai, C.-Y., Aebersold, R., Cramer, P., Chen, H.-T.: RNA polymerase III subunit architecture and implications for open promoter complex formation. Proc. Natl. Acad. Sci. U.S.A. 109, 19232-19237 (2012). doi:10.1073/pnas.1211665109

33. Lasker, K., Förster, F., Bohn, S., Walzthoeni, T., Villa, E., Unverdorben, P., Beck, F., Aebersold, R., Sali, A., Baumeister, W.: Molecular architecture of the 26S proteasome holocomplex determined by an integrative approach. Proc. Natl. Acad. Sci. U.S.A. 109, 1380-1387 (2012). doi:10.1073/pnas.1120559109

34. Soares, D.C., Bradshaw, N.J., Zou, J., Kennaway, C.K., Hamilton, R.S., Chen, Z.A., Wear, M.A., Blackburn, E.A., Bramham, J., Böttcher, B., Millar, J.K., Barlow, P.N., Walkinshaw, M.D., Rappsilber, J., Porteous, D.J.: The mitosis and neurodevelopment proteins NDE1 and NDEL1 form dimers, tetramers, and polymers with a folded back structure in solution. J. Biol. Chem. 287, 32381-32393 (2012). doi:10.1074/jbc.M112.393439

35. Lauber, M.A., Rappsilber, J., Reilly, J.P.: Dynamics of ribosomal protein S1 on a bacterial ribosome with cross-linking and mass spectrometry. Mol. Cell Proteomics. 11, 1965-1976 (2012). doi:10.1074/mcp.M112.019562

36. Pettelkau, J., Schröder, T., Ihling, C.H., Olausson, B.E.S., Kölbel, K., Lange, C., Sinz, A.: Structural Insights into retinal guanylylcyclase-GCAP-2 interaction determined by crosslinking and mass spectrometry. Biochemistry. 51, 4932-4949 (2012). doi:10.1021/bi300064v

37. Chavez, J.D., Cilia, M., Weisbrod, C.R., Ju, H.-J., Eng, J.K., Gray, S.M., Bruce, J.E.: Cross-linking measurements of the Potato leafroll virus reveal protein interaction topologies required for virion stability, aphid transmission, and virus-plant interactions. J. Proteome Res. 11, 2968-81 (2012). doi:10.1021/pr300041t 
38. Ido, K., Kakiuchi, S., Uno, C., Nishimura, T., Fukao, Y., Noguchi, T., Sato, F., Ifuku, K.: The conserved His-144 in the PsbP protein is important for the interaction between the PsbP N-terminus and the Cyt b559 subunit of photosystem II. J. Biol. Chem. 287, 2637726387 (2012). doi:10.1074/jbc.M112.385286

39. Yang, L., Zheng, C., Weisbrod, C.R., Tang, X., Munske, G.R., Hoopmann, M.R., Eng, J.K., Bruce, J.E.: In VIVO application of photocleavable protein interaction reporter technology. J. Proteome Res. 11, 1027-1041 (2012). doi:10.1021/pr200775j

40. Petrotchenko, E. V, Serpa, J.J., Hardie, D.B., Berjanskii, M., Suriyamongkol, B.P., Wishart, D.S., Borchers, C.H.: Use of Proteinase K Nonspecific Digestion for Selective and Comprehensive Identification of Interpeptide Cross-links: Application to Prion Proteins* $\square$ S Downloaded from. (2012). doi:10.1074/mcp.M111.013524

41. Clifford-Nunn, B., Showalter, H.D.H.H., Andrews, P.C.: Quaternary diamines as mass spectrometry cleavable crosslinkers for protein interactions. J. Am. Soc. Mass Spectrom. 23, 201-12 (2012). doi:10.1007/s13361-011-0288-4

42. Kao, A., Randall, A., Yang, Y., Patel, V.R., Kandur, W., Guan, S., Rychnovsky, S.D., Baldi, P., Huang, L.: Mapping the structural topology of the yeast 19S proteasomal regulatory particle using chemical cross-linking and probabilistic modeling. Mol. Cell. Proteomics. 11, 1566-1577 (2012). doi:10.1074/mcp.M112.018374

43. Leitner, A., Joachimiak, L.A.A., Bracher, A., Mönkemeyer, L., Walzthoeni, T., Chen, B., Pechmann, S., Holmes, S., Cong, Y., Ma, B., Ludtke, S., Chiu, W., Hartl, F.U.U., Aebersold, R., Frydman, J.: The Molecular Architecture of the Eukaryotic Chaperonin TRiC/CCT. Structure. 20, 814-825 (2012). doi:10.1016/j.str.2012.03.007

44. Herzog, F., Kahraman, A., Boehringer, D., Mak, R., Bracher, A., Walzthoeni, T., Leitner, A., Beck, M., Hartl, F.-U., Ban, N., Malmstrom, L., Aebersold, R.: Structural Probing of a Protein Phosphatase 2A Network by Chemical Cross-Linking and Mass Spectrometry. Science (80-. ). 337, 1348-1352 (2012). doi:10.1126/science.1221483

45. Herbst, S., Maucher, D., Schneider, M., Ihling, C.H., Jahn, O., Sinz, A.: Munc13-like skMLCK variants cannot mimic the unique calmodulin binding mode of Munc13 as evidenced by chemical cross-linking and mass spectrometry. PLoS One. 8, e75119 (2013). doi:10.1371/journal.pone.0075119

46. Pfaff, J., Hennig, J., Herzog, F., Aebersold, R., Sattler, M., Niessing, D., Meister, G.: Structural features of Argonaute-GW182 protein interactions. Proc. Natl. Acad. Sci. U.S.A. 110, E3770-9 (2013). doi:10.1073/pnas. 1308510110

47. Müller, M.Q., Ihling, C.H., Sinz, A.: Analyzing PPAR $\alpha /$ ligand interactions by chemical cross-linking and high-resolution mass spectrometry. Methods Mol. Biol. 952, 287-299 (2013). doi:10.1007/978-1-62703-155-4_21 
48. Rêgo, A.T., Holding, A.N., Kent, H., Lamers, M.H.: Architecture of the Pol III-clampexonuclease complex reveals key roles of the exonuclease subunit in processive DNA synthesis and repair. EMBO J. 32, 1334-1343 (2013). doi:10.1038/emboj.2013.68

49. Weisbrod, C.R., Chavez, J.D., Eng, J.K., Yang, L., Zheng, C., Bruce, J.E.: In vivo protein interaction network identified with a novel real-time cross-linked peptide identification strategy. J. Proteome Res. 12, 1569-1579 (2013). doi:10.1021/pr3011638

50. Pettelkau, J., Thondorf, I., Theisgen, S., Lilie, H., Schröder, T., Arlt, C., Ihling, C.H., Sinz, A.: Structural analysis of guanylyl cyclase-activating protein-2 (GCAP-2) homodimer by stable isotope-labeling, chemical cross-linking, and mass spectrometry. J. Am. Soc. Mass Spectrom. 24, 1969-1979 (2013). doi:10.1007/s13361-013-0734-6

51. Herbst, S., Masada, N., Pfennig, S., Ihling, C.H., Cooper, D.M.F., Sinz, A.: Structural insights into calmodulin/adenylyl cyclase 8 interaction. Anal Bioanal Chem. 405, 93339342 (2013). doi:10.1007/s00216-013-7358-3

52. Tosi, A., Haas, C., Herzog, F., Gilmozzi, A., Berninghausen, O., Ungewickell, C., Gerhold, C.B., Lakomek, K., Aebersold, R., Beckmann, R., Hopfner, K.-P.: Structure and subunit topology of the INO80 chromatin remodeler and its nucleosome complex. Cell. 154, 1207-1219 (2013). doi:10.1016/j.cell.2013.08.016

53. Serpa, J.J., Patterson, A.P., Pan, J., Han, J., Wishart, D.S., Petrotchenko, E. V, Borchers, C.H.: Using multiple structural proteomics approaches for the characterization of prion proteins. J Proteomics. 81, 31-42 (2013). doi:10.1016/j.jprot.2012.10.008

54. Tonkin, M.L., Arredondo, S.A., Loveless, B.C., Serpa, J.J., Makepeace, K.A.T., Sundar, N., Petrotchenko, E. V, Miller, L.H., Grigg, M.E., Boulanger, M.J.: Structural and biochemical characterization of Plasmodium falciparum 12 (Pf12) reveals a unique interdomain organization and the potential for an antiparallel arrangement with Pf41. J. Biol. Chem. 288, 12805-12817 (2013). doi:10.1074/jbc.M113.455667

55. Olson, A.L., Liu, F., Tucker, A.T., Goshe, M.B., Cavanagh, J.: Chemical crosslinking and LC/MS analysis to determine protein domain orientation: application to AbrB. Biochem. Biophys. Res. Commun. 431, 253-257 (2013). doi:10.1016/j.bbrc.2012.12.124

56. Rozbesky, D., Sovova, Z., Marcoux, J., Man, P., Ettrich, R., Robinson, C. V, Novak, P.: Structural model of lymphocyte receptor NKR-P1C revealed by mass spectrometry and molecular modeling. Anal. Chem. 85, 1597-1604 (2013). doi:10.1021/ac302860m

57. Thierbach, K., von Appen, A., Thoms, M., Beck, M., Flemming, D., Hurt, E.: Protein Interfaces of the Conserved Nup84 Complex from Chaetomium thermophilum Shown by Crosslinking Mass Spectrometry and Electron Microscopy. Structure. 21, 1672-1682 (2013) 
58. Chavez, J.D., Weisbrod, C.R., Zheng, C., Eng, J.K., Bruce, J.E.: Protein interactions, posttranslational modifications and topologies in human cells. Mol. Cell. Proteomics. 12, 1451-1467 (2013). doi:10.1074/mcp.M112.024497

59. Larivière, L., Plaschka, C., Seizl, M., Petrotchenko, E. V., Wenzeck, L., Borchers, C.H., Cramer, P.: Model of the Mediator middle module based on protein cross-linking. Nucleic Acids Res. 41, 9266-9273 (2013). doi:10.1093/nar/gkt704

60. Bui, K.H.H., von Appen, A., DiGuilio, A.L.L., Ori, A., Sparks, L., Mackmull, M.-T., Bock, T., Hagen, W., Andrés-Pons, A., Glavy, J.S.S., Beck, M., von Appen, A., DiGuilio, A.L.L., Ori, A., Sparks, L., Mackmull, M.-T., Bock, T., Hagen, W., Andrés-Pons, A., Glavy, J.S.S., Beck, M.: Integrated Structural Analysis of the Human Nuclear Pore Complex Scaffold. Cell. 155, 1233-1243 (2013). doi:10.1016/j.cell.2013.10.055

61. Kostan, J., Salzer, U., Orlova, A., Törö, I., Hodnik, V., Senju, Y., Zou, J., Schreiner, C., Steiner, J., Meriläinen, J., Nikki, M., Virtanen, I., Carugo, O., Rappsilber, J., Lappalainen, P., Lehto, V.-P., Anderluh, G., Egelman, E.H., Djinović-Carugo, K.: Direct interaction of actin filaments with F-BAR protein pacsin2. EMBO Rep. 15, 1154-1162 (2014). doi:10.15252/embr.201439267

62. Algret, R., Fernandez-Martinez, J., Shi, Y., Kim, S.J., Pellarin, R., Cimermancic, P., Cochet, E., Sali, A., Chait, B.T., Rout, M.P., Dokudovskaya, S.: Molecular architecture and function of the SEA complex, a modulator of the TORC1 pathway. Mol. Cell Proteomics. 13, 2855-2870 (2014). doi:10.1074/mcp.M114.039388

63. Christian, H., Hofele, R. V, Urlaub, H., Ficner, R.: Insights into the activation of the helicase Prp43 by biochemical studies and structural mass spectrometry. Nucleic Acids Res. 42, 1162-1179 (2014). doi:10.1093/nar/gkt985

64. Erzberger, J.P., Stengel, F., Pellarin, R., Zhang, S., Schaefer, T., Aylett, C.H.S., Cimermančič, P., Boehringer, D., Sali, A., Aebersold, R., Ban, N.: Molecular Architecture of the 40S·eIF1·eIF3 Translation Initiation Complex. Cell. 158, 1123-1135 (2014)

65. Hornung, P., Troc, P., Malvezzi, F., Maier, M., Demianova, Z., Zimniak, T., Litos, G., Lampert, F., Schleiffer, A., Brunner, M., Mechtler, K., Herzog, F., Marlovits, T.C., Westermann, S.: A cooperative mechanism drives budding yeast kinetochore assembly downstream of CENP-A. J. Cell Biol. 206, 509-524 (2014). doi:10.1083/jcb.201403081

66. Gordiyenko, Y., Schmidt, C., Jennings, M.D., Matak-Vinkovic, D., Pavitt, G.D., Robinson, C. V: eIF2B is a decameric guanine nucleotide exchange factor with a $\gamma 2 \varepsilon 2$ tetrameric core. Nat Commun. 5, 3902 (2014). doi:10.1038/ncomms4902

67. in 't Veld, P.J.H., Herzog, F., Ladurner, R., Davidson, I.F., Piric, S., Kreidl, E., Bhaskara, V., Aebersold, R., Peters, J.-M.: Characterization of a DNA exit gate in the human cohesin ring. Science (80-. ). 346, 968-972 (2014). doi:10.1126/science. 1256904 
68. Cevher, M.A., Shi, Y., Li, D., Chait, B.T., Malik, S., Roeder, R.G.: Reconstitution of active human core Mediator complex reveals a critical role of the MED14 subunit. Nat. Struct. Mol. Biol. 21, 1028-1034 (2014). doi:10.1038/nsmb.2914

69. Shukla, A.K., Westfield, G.H., Xiao, K., Reis, R.I., Huang, L.-Y., Tripathi-Shukla, P., Qian, J., Li, S., Blanc, A., Oleskie, A.N., Dosey, A.M., Su, M., Liang, C.-R., Gu, L.-L., Shan, J.-M., Chen, X., Hanna, R., Choi, M., Yao, X.J., Klink, B.U., Kahsai, A.W., Sidhu, S.S., Koide, S., Penczek, P.A., Kossiakoff, A.A., Woods, V.L., Kobilka, B.K., Skiniotis, G., Lefkowitz, R.J.: Visualization of arrestin recruitment by a G-protein-coupled receptor. Nature. 512, 218-222 (2014). doi:10.1038/nature13430

70. Kube, S., Kapitein, N., Zimniak, T., Herzog, F., Mogk, A., Wendler, P.: Structure of the VipA/B type VI secretion complex suggests a contraction-state-specific recycling mechanism. Cell Rep. 8, 20-30 (2014). doi:10.1016/j.celrep.2014.05.034

71. Han, Y., Luo, J., Ranish, J., Hahn, S.: Architecture of the Saccharomyces cerevisiae SAGA transcription coactivator complex. EMBO J. 33, 2534-2546 (2014). doi:10.15252/embj.201488638

72. Piazza, I., Rutkowska, A., Ori, A., Walczak, M., Metz, J., Pelechano, V., Beck, M., Haering, C.H.: Association of condensin with chromosomes depends on DNA binding by its HEAT-repeat subunits. Nat. Struct. Mol. Biol. 21, 560-568 (2014). doi:10.1038/nsmb.2831

73. Mühlbacher, W., Sainsbury, S., Hemann, M., Hantsche, M., Neyer, S., Herzog, F., Cramer, P.: Conserved architecture of the core RNA polymerase II initiation complex. Nat Commun. 5, 4310 (2014). doi:10.1038/ncomms5310

74. Olson, A.L., Tucker, A.T., Bobay, B.G., Soderblom, E.J., Moseley, M.A., Thompson, R.J., Cavanagh, J.: Structure and DNA-binding traits of the transition state regulator AbrB. Structure. 22, 1650-1656 (2014). doi:10.1016/j.str.2014.08.018

75. Zorn, M., Ihling, C.H., Golbik, R., Sawers, R.G., Sinz, A.: Mapping cell envelope and periplasm protein interactions of Escherichia coli respiratory formate dehydrogenases by chemical cross-linking and mass spectrometry. J. Proteome Res. 13, 5524-5535 (2014). doi:10.1021/pr5004906

76. Basilico, F., Maffini, S., Weir, J.R., Prumbaum, D., Rojas, A.M., Zimniak, T., Antoni, A. De, Jeganathan, S., Voss, B., van Gerwen, S., Krenn, V., Massimiliano, L., Valencia, A., Vetter, I.R., Herzog, F., Raunser, S., Pasqualato, S., Musacchio, A.: The pseudo GTPase CENP-M drives human kinetochore assembly. Elife. 3, e02978 (2014). doi:10.7554/eLife.02978

77. Doberenz, C., Zorn, M., Falke, D., Nannemann, D., Hunger, D., Beyer, L., Ihling, C.H., Meiler, J., Sinz, A., Sawers, R.G.: Pyruvate formate-lyase interacts directly with the 
formate channel FocA to regulate formate translocation. J. Mol. Biol. 426, 2827-2839 (2014). doi:10.1016/j.jmb.2014.05.023

78. Lössl, P., Kölbel, K., Tänzler, D., Nannemann, D., Ihling, C.H., Keller, M. V, Schneider, M., Zaucke, F., Meiler, J., Sinz, A.: Analysis of nidogen-1/laminin $\gamma 1$ interaction by crosslinking, mass spectrometry, and computational modeling reveals multiple binding modes. PLoS One. 9, e112886 (2014). doi:10.1371/journal.pone.0112886

79. Abad, M.A., Medina, B., Santamaria, A., Zou, J., Plasberg-Hill, C., Madhumalar, A., Jayachandran, U., Redli, P.M., Rappsilber, J., Nigg, E.A., Jeyaprakash, A.A.: Structural basis for microtubule recognition by the human kinetochore Ska complex. Nat Commun. 5, 2964 (2014). doi:10.1038/ncomms3964

80. Liu, H., Zhang, H., Weisz, D.A., Vidavsky, I., Gross, M.L., Pakrasi, H.B.: MS-based cross-linking analysis reveals the location of the PsbQ protein in cyanobacterial photosystem II. Proc. Natl. Acad. Sci. U.S.A. 111, 4638-4643 (2014). doi:10.1073/pnas.1323063111

81. Yu, C., Kandur, W., Kao, A., Rychnovsky, S., Huang, L.: Developing new isotope-coded mass spectrometry-cleavable cross-linkers for elucidating protein structures. Anal. Chem. 86, 2099-106 (2014). doi:10.1021/ac403636b

82. Buncherd, H., Roseboom, W., de Koning, L.J., de Koster, C.G., de Jong, L.: A gas phase cleavage reaction of cross-linked peptides for protein complex topology studies by peptide fragment fingerprinting from large sequence database. J. Proteomics. 108, 65-77 (2014). doi:10.1016/j.jprot.2014.05.003

83. He, G., Zhang, H., King, J.D., Blankenship, R.E.: Structural analysis of the homodimeric reaction center complex from the photosynthetic green sulfur bacterium Chlorobaculum tepidum. Biochemistry. 53, 4924-4930 (2014). doi:10.1021/bi5006464

84. Benda, C., Ebert, J., Scheltema, R.A., Schiller, H.B., Baumgärtner, M., Bonneau, F., Mann, M., Conti, E.: Structural model of a CRISPR RNA-silencing complex reveals the RNA-target cleavage activity in Cmr4. Mol. Cell. 56, 43-54 (2014). doi:10.1016/j.molcel.2014.09.002

85. Leitner, A., Joachimiak, L.A., Unverdorben, P., Walzthoeni, T., Frydman, J., Förster, F., Aebersold, R.: Chemical cross-linking/mass spectrometry targeting acidic residues in proteins and protein complexes. Proc. Natl. Acad. Sci. U. S. A. 111, 9455-9460 (2014). doi:10.1073/pnas.1320298111

86. Shi, Y., Fernandez-Martinez, J., Tjioe, E., Pellarin, R., Kim, S.J., Williams, R., Schneidman-Duhovny, D., Sali, A., Rout, M.P., Chait, B.T.: Structural Characterization by Cross-linking Reveals the Detailed Architecture of a Coatomer-related Heptameric Module from the Nuclear Pore Complex. Mol. Cell. Proteomics. 13, 2927-2943 (2014). doi:10.1074/mcp.M114.041673 
87. Greber, B.J., Boehringer, D., Leibundgut, M., Bieri, P., Leitner, A., Schmitz, N., Aebersold, R., Ban, N.: The complete structure of the large subunit of the mammalian mitochondrial ribosome. Nature. 515, 283-6 (2014). doi:10.1038/nature13895

88. Tal, O., Trabelcy, B., Gerchman, Y., Adir, N.: Investigation of phycobilisome subunit interaction interfaces by coupled cross-linking and mass spectrometry. J. Biol. Chem. 289, 33084-97 (2014). doi:10.1074/jbc.M114.595942

89. Ido, K., Nield, J., Fukao, Y., Nishimura, T., Sato, F., Ifuku, K.: Cross-linking evidence for multiple interactions of the PsbP and PsbQ proteins in a higher plant photosystem II supercomplex. J. Biol. Chem. 289, 20150-7 (2014). doi:10.1074/jbc.M114.574822

90. Kaake, R.M., Wang, X., Burke, A., Yu, C., Kandur, W., Yang, Y., Novtisky, E.J., Second, T., Duan, J., Kao, A., Guan, S., Vellucci, D., Rychnovsky, S.D., Huang, L., Secondt, T., Duan, J., Kao, A., Guan, S., Vellucci, D., Rychnovsky, S.D., Huang, L., Novtisky, E.J., Kao, A., Yang, Y., Rychnovsky, S.D., Second, T., Kaake, R.M., Kandur, W., Burke, A., Guan, S., Yu, C., Duan, J., Vellucci, D., Wang, X., Burke, A., Yu, C., Kandur, W., Yang, Y., Novtisky, E.J., Second, T., Duan, J., Kao, A., Guan, S., Vellucci, D., Rychnovsky, S.D., Huang, L.: A New in Vivo Cross-linking Mass Spectrometry Platform to Define Protein-Protein Interactions in Living Cells. Mol. Cell. Proteomics. 13, 3533-3543 (2014). doi:10.1074/mcp.m114.042630

91. Morgner, N., Schmidt, C., Beilsten-Edmands, V., Ebong, I.-O., Patel, N.A., Clerico, E.M., Kirschke, E., Daturpalli, S., Jackson, S.E., Agard, D., Robinson, C. V: Hsp70 forms antiparallel dimers stabilized by post-translational modifications to position clients for transfer to Hsp90. Cell Rep. 11, 759-769 (2015). doi:10.1016/j.celrep.2015.03.063

92. Chavez, J.D., Schweppe, D.K., Eng, J.K., Zheng, C., Taipale, A., Zhang, Y., Takara, K., Bruce, J.E.: Quantitative interactome analysis reveals a chemoresistant edgotype. Nat Commun. 6, 7928 (2015). doi:10.1038/ncomms8928

93. Chew, L.H., Lu, S., Liu, X., Li, F.K., Yu, A.Y., Klionsky, D.J., Dong, M.-Q., Yip, C.K.: Molecular interactions of the Saccharomyces cerevisiae Atg1 complex provide insights into assembly and regulatory mechanisms. Autophagy. 11, 891-905 (2015). doi:10.1080/15548627.2015.1040972

94. Zelter, A., Bonomi, M., Kim, J.O., Umbreit, N.T., Hoopmann, M.R., Johnson, R., Riffle, M., Jaschob, D., MacCoss, M.J., Moritz, R.L., Davis, T.N.: The molecular architecture of the Dam1 kinetochore complex is defined by cross-linking based structural modelling. Nat Commun. 6, 8673 (2015). doi:10.1038/ncomms9673

95. Sun, J., Shi, Y., Georgescu, R.E., Yuan, Z., Chait, B.T., Li, H., O’Donnell, M.E.: The architecture of a eukaryotic replisome. Nat. Struct. Mol. Biol. 22, 976-982 (2015). doi:10.1038/nsmb.3113 
96. Kadavath, H., Hofele, R. V, Biernat, J., Kumar, S., Tepper, K., Urlaub, H., Mandelkow, E., Zweckstetter, M.: Tau stabilizes microtubules by binding at the interface between tubulin heterodimers. Proc. Natl. Acad. Sci. U.S.A. 112, 7501-7506 (2015). doi:10.1073/pnas.1504081112

97. Kock, M., Nunes, M.M., Hemann, M., Kube, S., Jürgen Dohmen, R., Herzog, F., Ramos, P.C., Wendler, P.: Proteasome assembly from $15 \mathrm{~S}$ precursors involves major conformational changes and recycling of the Pba1-Pba2 chaperone. Nat. Commun. 6, 6123 (2015). doi:10.1038/ncomms7123

98. Trowitzsch, S., Viola, C., Scheer, E., Conic, S., Chavant, V., Fournier, M., Papai, G., Ebong, I.-O., Schaffitzel, C., Zou, J., Haffke, M., Rappsilber, J., Robinson, C. V, Schultz, P., Tora, L., Berger, I.: Cytoplasmic TAF2-TAF8-TAF10 complex provides evidence for nuclear holo-TFIID assembly from preformed submodules. Nat Commun. 6, 6011 (2015). doi: $10.1038 /$ ncomms 7011

99. Plaschka, C., Larivière, L., Wenzeck, L., Seizl, M., Hemann, M., Tegunov, D., Petrotchenko, E. V., Borchers, C.H., Baumeister, W., Herzog, F., Villa, E., Cramer, P.: Architecture of the RNA polymerase II-Mediator core initiation complex. Nature. 518, 376-380 (2015). doi:10.1038/nature14229

100. Absmeier, E., Wollenhaupt, J., Mozaffari-Jovin, S., Becke, C., Lee, C.-T., Preussner, M., Heyd, F., Urlaub, H., Lührmann, R., Santos, K.F., Wahl, M.C.: The large N-terminal region of the Brr2 RNA helicase guides productive spliceosome activation. Genes Dev. 29, 2576-2587 (2015). doi:10.1101/gad.271528.115

101. Male, G., von Appen, A., Glatt, S., Taylor, N.M.I., Cristovao, M., Groetsch, H., Beck, M., Müller, C.W.: Architecture of TFIIIC and its role in RNA polymerase III pre-initiation complex assembly. Nat Commun. 6, 7387 (2015). doi:10.1038/ncomms8387

102. LoPiccolo, J., Kim, S.J., Shi, Y., Wu, B., Wu, H., Chait, B.T., Singer, R.H., Sali, A., Brenowitz, M., Bresnick, A.R., Backer, J.M.: Assembly and Molecular Architecture of the Phosphoinositide 3-Kinase p85a Homodimer. J. Biol. Chem. 290, 30390-30405 (2015). doi:10.1074/jbc.M115.689604

103. Klare, K., Weir, J.R., Basilico, F., Zimniak, T., Massimiliano, L., Ludwigs, N., Herzog, F., Musacchio, A.: CENP-C is a blueprint for constitutive centromere-associated network assembly within human kinetochores. J. Cell Biol. 210, 11-22 (2015). doi:10.1083/jcb.201412028

104. Beilsten-Edmands, V., Gordiyenko, Y., Kung, J.C., Mohammed, S., Schmidt, C., Robinson, C. V: eIF2 interactions with initiator tRNA and eIF2B are regulated by posttranslational modifications and conformational dynamics. Cell Discov. 1, 15020 (2015). doi:10.1038/celldisc.2015.20 
105. Nillegoda, N.B., Kirstein, J., Szlachcic, A., Berynskyy, M., Stank, A., Stengel, F., Arnsburg, K., Gao, X., Scior, A., Aebersold, R., Guilbride, D.L., Wade, R.C., Morimoto, R.I., Mayer, M.P., Bukau, B.: Crucial HSP70 co-chaperone complex unlocks metazoan protein disaggregation. Nature. 524, 247-251 (2015). doi:10.1038/nature14884

106. Brodie, N.I., Makepeace, K.A.T., Petrotchenko, E. V, Borchers, C.H.: Isotopically-coded short-range hetero-bifunctional photo-reactive crosslinkers for studying protein structure. J Proteomics. 118, 12-20 (2015). doi:10.1016/j.jprot.2014.08.012

107. Martinez-Rucobo, F.W., Kohler, R., van de Waterbeemd, M., Heck, A.J.R., Hemann, M., Herzog, F., Stark, H., Cramer, P.: Molecular Basis of Transcription-Coupled Pre-mRNA Capping. Mol. Cell. 58, 1079-1089 (2015). doi:10.1016/j.molcel.2015.04.004

108. Nury, C., Redeker, V., Dautrey, S., Romieu, A., van der Rest, G., Renard, P.-Y., Melki, R., Chamot-Rooke, J.: A novel bio-orthogonal cross-linker for improved protein/protein interaction analysis. Anal. Chem. 87, 1853-1860 (2015). doi:10.1021/ac503892c

109. Politis, A., Schmidt, C., Tjioe, E., Sandercock, A.M., Lasker, K., Gordiyenko, Y., Russel, D., Sali, A., Robinson, C. V: Topological models of heteromeric protein assemblies from mass spectrometry: application to the yeast eIF3:eIF5 complex. Chem. Biol. 22, 117-128 (2015). doi:10.1016/j.chembiol.2014.11.010

110. Efremov, R.G., Leitner, A., Aebersold, R., Raunser, S.: Architecture and conformational switch mechanism of the ryanodine receptor. Nature. 517, 39-43 (2015). doi:10.1038/nature13916

111. Rivera-Santiago, R.F., Harper, S.L., Zhou, S., Sriswasdi, S., Feinstein, S.I., Fisher, A.B., Speicher, D.W.: Solution structure of the reduced form of human peroxiredoxin-6 elucidated using zero-length chemical cross-linking and homology modelling. Biochem. J. 468, 87-98 (2015). doi:10.1042/BJ20141463

112. Robinson, P.J., Trnka, M.J., Pellarin, R., Greenberg, C.H., Bushnell, D.A., Davis, R., Burlingame, A.L., Sali, A., Kornberg, R.D.: Molecular architecture of the yeast Mediator complex. Elife. 4, (2015). doi:10.7554/eLife.08719

113. Pleiner, T., Bates, M., Trakhanov, S., Lee, C.-T., Schliep, J.E., Chug, H., Böhning, M., Stark, H., Urlaub, H., Görlich, D.: Nanobodies: site-specific labeling for super-resolution imaging, rapid epitope-mapping and native protein complex isolation. Elife. 4, e11349 (2015). doi:10.7554/eLife.11349

114. Deniaud, A., Karuppasamy, M., Bock, T., Masiulis, S., Huard, K., Garzoni, F., Kerschgens, K., Hentze, M.W., Kulozik, A.E., Beck, M., Neu-Yilik, G., Schaffitzel, C.: A network of SMG-8, SMG-9 and SMG-1 C-terminal insertion domain regulates UPF1 substrate recruitment and phosphorylation. Nucleic Acids Res. 43, 7600-7611 (2015). doi:10.1093/nar/gkv668 
115. Gaik, M., Flemming, D., von Appen, A., Kastritis, P., Mücke, N., Fischer, J., Stelter, P., Ori, A., Bui, K.H., Baßler, J., Barbar, E., Beck, M., Hurt, E.: Structural basis for assembly and function of the Nup82 complex in the nuclear pore scaffold. J. Cell Biol. 208, 283297 (2015). doi:10.1083/jcb.201411003

116. Gaubitz, C., Oliveira, T.M., Prouteau, M., Leitner, A., Karuppasamy, M., Konstantinidou, G., Rispal, D., Eltschinger, S., Robinson, G.C., Thore, S., Aebersold, R., Schaffitzel, C., Loewith, R.: Molecular Basis of the Rapamycin Insensitivity of Target Of Rapamycin Complex 2. Mol. Cell. 58, 977-988 (2015). doi:10.1016/j.molcel.2015.04.031

117. Barysz, H., Kim, J.H., Chen, Z.A., Hudson, D.F., Rappsilber, J., Gerloff, D.L., Earnshaw, W.C.: Three-dimensional topology of the SMC2/SMC4 subcomplex from chicken condensin I revealed by cross-linking and molecular modelling. Open Biol. 5, 150005 (2015). doi:10.1098/rsob.150005

118. Yu, C., Mao, H., Novitsky, E.J., Tang, X., Rychnovsky, S.D., Zheng, N., Huang, L.: Gln40 deamidation blocks structural reconfiguration and activation of SCF ubiquitin ligase complex by Nedd8. Nat Commun. 6, 10053 (2015). doi:10.1038/ncomms10053

119. Calviño, F.R., Kharde, S., Ori, A., Hendricks, A., Wild, K., Kressler, D., Bange, G., Hurt, E., Beck, M., Sinning, I.: Symportin 1 chaperones 5S RNP assembly during ribosome biogenesis by occupying an essential rRNA-binding site. Nat Commun. 6, 6510 (2015). doi: $10.1038 /$ ncomms 7510

120. van Maldegem, F., Maslen, S., Johnson, C.M., Chandra, A., Ganesh, K., Skehel, M., Rada, C.: CTNNBL1 facilitates the association of CWC15 with CDC5L and is required to maintain the abundance of the Prp19 spliceosomal complex. Nucleic Acids Res. 43, 70587069 (2015). doi:10.1093/nar/gkv643

121. Port, S.A., Monecke, T., Dickmanns, A., Spillner, C., Hofele, R., Urlaub, H., Ficner, R., Kehlenbach, R.H.: Structural and Functional Characterization of CRM1-Nup214 Interactions Reveals Multiple FG-Binding Sites Involved in Nuclear Export. Cell Rep. 13, 690-702 (2015). doi:10.1016/j.celrep.2015.09.042

122. Schweppe, D.K., Harding, C., Chavez, J.D., Wu, X., Ramage, E., Singh, P.K., Manoil, C., Bruce, J.E.: Host-Microbe Protein Interactions during Bacterial Infection. Chem. Biol. 22, 1521-1530 (2015). doi:10.1016/j.chembiol.2015.09.015

123. Liu, J., Yu, C., Hu, X., Kim, J.K., Bierma, J.C., Jun, H.I., Rychnovsky, S.D., Huang, L., Qiao, F.: Dissecting Fission Yeast Shelterin Interactions via MICro-MS Links Disruption of Shelterin Bridge to Tumorigenesis. Cell Rep. 12, 2169-2180 (2015). doi:10.1016/j.celrep.2015.08.043

124. Solomonson, M., Setiaputra, D., Makepeace, K.A.T., Lameignere, E., Petrotchenko, E. V., Conrady, D.G., Bergeron, J.R., Vuckovic, M., Dimaio, F., Borchers, C.H., Yip, C.K., 
Strynadka, N.C.J.: Structure of EspB from the ESX-1 type VII secretion system and insights into its export mechanism. Structure. (2015). doi:10.1016/j.str.2015.01.002

125. Greber, B.J., Bieri, P., Leibundgut, M., Leitner, A., Aebersold, R., Boehringer, D., Ban, N.: Ribosome. The complete structure of the 55S mammalian mitochondrial ribosome. Science (80-. ). 348, 303-308 (2015). doi:10.1126/science.aaa3872

126. Arlt, C., Ihling, C.H., Sinz, A.: Structure of full-length p53 tumor suppressor probed by chemical cross-linking and mass spectrometry. Proteomics. (2015). doi:10.1002/pmic.201400549

127. Navare, A.T., Chavez, J.D., Zheng, C., Weisbrod, C.R., Eng, J.K., Siehnel, R., Singh, P.K., Manoil, C., Bruce, J.E., Rajani, S., Archana, R., Indla, Y.R., Rajesh, P., Navare, A.T., Chavez, J.D., Zheng, C., Weisbrod, C.R., Eng, J.K., Siehnel, R., Singh, P.K., Manoil, C., Bruce, J.E.: Probing the protein interaction network of Pseudomonas aeruginosa cells by chemical cross-linking mass spectrometry. Structure. 23, 762-773 (2015). doi:10.1016/j.str.2015.01.022

128. Brodie, N.I., Petrotchenko, E. V, Borchers, C.H.: The novel isotopically coded short-range photo-reactive crosslinker 2,4,6-triazido-1,3,5-triazine (TATA) for studying protein structures. J Proteomics. 149, 69-76 (2016). doi:10.1016/j.jprot.2016.02.024

129. Ellard, K., Serpa, J.J., Petrotchenko, E. V, Borchers, C.H., Ausió, J.: Expression and purification of the full murine NPM2 and study of its interaction with protamines and histones. Biochem Biophys Rep. 6, 165-171 (2016). doi:10.1016/j.bbrep.2016.04.002

130. Sheppard, C., Blombach, F., Belsom, A., Schulz, S., Daviter, T., Smollett, K., Mahieu, E., Erdmann, S., Tinnefeld, P., Garrett, R., Grohmann, D., Rappsilber, J., Werner, F.: Repression of RNA polymerase by the archaeo-viral regulator ORF145/RIP. Nat Commun. 7, 13595 (2016). doi:10.1038/ncomms13595

131. Abad, M.A., Zou, J., Medina-Pritchard, B., Nigg, E.A., Rappsilber, J., Santamaria, A., Jeyaprakash, A.A.: Ska3 Ensures Timely Mitotic Progression by Interacting Directly With Microtubules and Ska1 Microtubule Binding Domain. Sci Rep. 6, 34042 (2016). doi:10.1038/srep34042

132. Wen, Y., Sobott, F., Devreese, B.: ATP and autophosphorylation driven conformational changes of HipA kinase revealed by ion mobility and crosslinking mass spectrometry. Anal Bioanal Chem. 408, 5925-5933 (2016). doi:10.1007/s00216-016-9709-3

133. Cretu, C., Schmitzová, J., Ponce-Salvatierra, A., Dybkov, O., Laurentiis, E.I. De, Sharma, K., Will, C.L., Urlaub, H., Lührmann, R., Pena, V.: Molecular Architecture of SF3b and Structural Consequences of Its Cancer-Related Mutations. Mol. Cell. 64, 307-319 (2016). doi:10.1016/j.molcel.2016.08.036 
134. Agafonov, D.E., Kastner, B., Dybkov, O., Hofele, R. V, Liu, W.-T., Urlaub, H., Lührmann, R., Stark, H.: Molecular architecture of the human U4/U6.U5 tri-snRNP. Science (80-. ). 351, 1416-1420 (2016). doi:10.1126/science.aad2085

135. Al-Eryani, Y., Rasmussen, M.I., Kjellström, S., Højrup, P., Emanuelsson, C., von Wachenfeldt, C.: Exploring structure and interactions of the bacterial adaptor protein $\mathrm{YjbH}$ by crosslinking mass spectrometry. Proteins. 84, 1234-1245 (2016). doi:10.1002/prot. 25072

136. Vos, S.M., Pöllmann, D., Caizzi, L., Hofmann, K.B., Rombaut, P., Zimniak, T., Herzog, F., Cramer, P.: Architecture and RNA binding of the human negative elongation factor. Elife. 5, (2016). doi:10.7554/eLife.14981

137. Chen, Z.A., Pellarin, R., Fischer, L., Sali, A., Nilges, M., Barlow, P.N., Rappsilber, J.: Structure of Complement C3(H2O) Revealed By Quantitative Cross-Linking/Mass Spectrometry And Modeling. Mol. Cell Proteomics. 15, 2730-2743 (2016). doi:10.1074/mcp.M115.056473

138. Altunkaya, G.P., Malvezzi, F., Demianova, Z., Zimniak, T., Litos, G., Weissmann, F., Mechtler, K., Herzog, F., Westermann, S.: CCAN Assembly Configures Composite Binding Interfaces to Promote Cross-Linking of Ndc80 Complexes at the Kinetochore. Curr. Biol. 26, 2370-2378 (2016). doi:10.1016/j.cub.2016.07.005

139. Rauhut, R., Fabrizio, P., Dybkov, O., Hartmuth, K., Pena, V., Chari, A., Kumar, V., Lee, C.-T., Urlaub, H., Kastner, B., Stark, H., Lührmann, R.: Molecular architecture of the Saccharomyces cerevisiae activated spliceosome. Science (80-. ). 353, 1399-1405 (2016). doi:10.1126/science.aag1906

140. Guaitoli, G., Raimondi, F., Gilsbach, B.K., Gómez-Llorente, Y., Deyaert, E., Renzi, F., Li, X., Schaffner, A., Jagtap, P.K.A., Boldt, K., von Zweydorf, F., Gotthardt, K., Lorimer, D.D., Yue, Z., Burgin, A., Janjic, N., Sattler, M., Versées, W., Ueffing, M., UbarretxenaBelandia, I., Kortholt, A., Gloeckner, C.J.: Structural model of the dimeric Parkinson's protein LRRK2 reveals a compact architecture involving distant interdomain contacts. Proc. Natl. Acad. Sci. U.S.A. 113, E4357-66 (2016). doi:10.1073/pnas.1523708113

141. Gallego, L.D., Steger, M.G., Polyansky, A.A., Schubert, T., Zagrovic, B., Zheng, N., Clausen, T., Herzog, F., Köhler, A.: Structural mechanism for the recognition and ubiquitination of a single nucleosome residue by Rad6-Bre1. Proc. Natl. Acad. Sci. U.S.A. 113, 10553-10558 (2016). doi:10.1073/pnas.1606863113

142. Häupl, B., Ihling, C.H., Sinz, A.: Protein Interaction Network of Human Protein Kinase D2 Revealed by Chemical Cross-Linking/Mass Spectrometry. J. Proteome Res. 15, 36863699 (2016). doi:10.1021/acs.jproteome.6b00513

143. Lampi, K.J., Murray, M.R., Peterson, M.P., Eng, B.S., Yue, E., Clark, A.R., Barbar, E., David, L.L.: Differences in solution dynamics between lens $\beta$-crystallin homodimers and 
heterodimers probed by hydrogen-deuterium exchange and deamidation. Biochim. Biophys. Acta. 1860, 304-314 (2016). doi:10.1016/j.bbagen.2015.06.014

144. Greber, B.J., Gerhardy, S., Leitner, A., Leibundgut, M., Salem, M., Boehringer, D., Leulliot, N., Aebersold, R., Panse, V.G., Ban, N.: Insertion of the Biogenesis Factor Rei1 Probes the Ribosomal Tunnel during 60S Maturation. Cell. 164, 91-102 (2016). doi:10.1016/j.cell.2015.11.027

145. Makowski, M.M., Willems, E., Jansen, P.W.T.C., Vermeulen, M.: Cross-linking immunoprecipitation-MS (xIP-MS): Topological Analysis of Chromatin-associated Protein Complexes Using Single Affinity Purification. Mol. Cell Proteomics. 15, 854-865 (2016). doi:10.1074/mcp.M115.053082

146. Lössl, P., Brunner, A.M., Liu, F., Leney, A.C., Yamashita, M., Scheltema, R.A., Heck, A.J.R.: Deciphering the Interplay among Multisite Phosphorylation, Interaction Dynamics, and Conformational Transitions in a Tripartite Protein System. ACS Cent Sci. 2, 445-455 (2016). doi:10.1021/acscentsci.6b00053

147. Petrovic, A., Keller, J., Liu, Y., Overlack, K., John, J., Dimitrova, Y.N., Jenni, S., van Gerwen, S., Stege, P., Wohlgemuth, S., Rombaut, P., Herzog, F., Harrison, S.C., Vetter, I.R., Musacchio, A.: Structure of the MIS12 Complex and Molecular Basis of Its Interaction with CENP-C at Human Kinetochores. Cell. 167, 1028-1040.e15 (2016). doi:10.1016/j.cell.2016.10.005

148. Kim, D., Setiaputra, D., Jung, T., Chung, J., Leitner, A., Yoon, J., Aebersold, R., Hebert, H., Yip, C.K., Song, J.-J.: Molecular Architecture of Yeast Chromatin Assembly Factor 1. Sci Rep. 6, 26702 (2016). doi:10.1038/srep26702

149. Mosadeghi, R., Reichermeier, K.M., Winkler, M., Schreiber, A., Reitsma, J.M., Zhang, Y., Stengel, F., Cao, J., Kim, M., Sweredoski, M.J., Hess, S., Leitner, A., Aebersold, R., Peter, M., Deshaies, R.J., Enchev, R.I.: Structural and kinetic analysis of the COP9Signalosome activation and the cullin-RING ubiquitin ligase deneddylation cycle. Elife. 5, (2016). doi:10.7554/eLife.12102

150. Hons, M.T., Veld, P.J.H. In 't, Kaesler, J., Rombaut, P., Schleiffer, A., Herzog, F., Stark, H., Peters, J.-M.: Topology and structure of an engineered human cohesin complex bound to Pds5B. Nat Commun. 7, 12523 (2016). doi:10.1038/ncomms 12523

151. Chavez, J.D., Schweppe, D.K., Eng, J.K., Bruce, J.E.: In Vivo Conformational Dynamics of Hsp90 and Its Interactors. Cell Chem. Biol. 23, 716-726 (2016). doi:10.1016/j.chembiol.2016.05.012

152. Hiragami-Hamada, K., Soeroes, S., Nikolov, M., Wilkins, B., Kreuz, S., Chen, C., RosaVelázquez, I.A.D. La, Zenn, H.M., Kost, N., Pohl, W., Chernev, A., Schwarzer, D., Jenuwein, T., Lorincz, M., Zimmermann, B., Walla, P.J., Neumann, H., Baubec, T., Urlaub, H., Fischle, W.: Dynamic and flexible H3K9me3 bridging via HP1 $\beta$ dimerization 
establishes a plastic state of condensed chromatin. Nat Commun. 7, 11310 (2016). doi:10.1038/ncomms 11310

153. Kiosze-Becker, K., Ori, A., Gerovac, M., Heuer, A., Nürenberg-Goloub, E., Rashid, U.J., Becker, T., Beckmann, R., Beck, M., Tampé, R.: Structure of the ribosome post-recycling complex probed by chemical cross-linking and mass spectrometry. Nat Commun. 7, 13248 (2016). doi:10.1038/ncomms 13248

154. McCaughan, U.M., Jayachandran, U., Shchepachev, V., Chen, Z.A., Rappsilber, J., Tollervey, D., Cook, A.G.: Pre-40S ribosome biogenesis factor Tsr1 is an inactive structural mimic of translational GTPases. Nat Commun. 7, 11789 (2016). doi:10.1038/ncomms 11789

155. Poli, J., Gerhold, C.-B., Tosi, A., Hustedt, N., Seeber, A., Sack, R., Herzog, F., Pasero, P., Shimada, K., Hopfner, K.-P., Gasser, S.M.: Mec1, INO80, and the PAF1 complex cooperate to limit transcription replication conflicts through RNAPII removal during replication stress. Genes Dev. 30, 337-354 (2016). doi:10.1101/gad.273813.115

156. Heuck, A., Schitter-Sollner, S., Suskiewicz, M.J., Kurzbauer, R., Kley, J., Schleiffer, A., Rombaut, P., Herzog, F., Clausen, T.: Structural basis for the disaggregase activity and regulation of Hsp104. Elife. 5, (2016). doi:10.7554/eLife.21516

157. Bernecky, C., Herzog, F., Baumeister, W., Plitzko, J.M., Cramer, P.: Structure of transcribing mammalian RNA polymerase II. Nature. 529, 551-554 (2016). doi:10.1038/nature16482

158. Friese, A., Faesen, A.C., in 't Veld, P.J.H., Fischböck, J., Prumbaum, D., Petrovic, A., Raunser, S., Herzog, F., Musacchio, A.: Molecular requirements for the inter-subunit interaction and kinetochore recruitment of SKAP and Astrin. Nat Commun. 7, 11407 (2016). doi:10.1038/ncomms 11407

159. Fernandez-Martinez, J., Kim, S.J., Shi, Y., Upla, P., Pellarin, R., Gagnon, M., Chemmama, I.E., Wang, J., Nudelman, I., Zhang, W., Williams, R., Rice, W.J., Stokes, D.L., Zenklusen, D., Chait, B.T., Sali, A., Rout, M.P.: Structure and Function of the Nuclear Pore Complex Cytoplasmic mRNA Export Platform. Cell. 167, 1215-1228.e25 (2016). doi:10.1016/j.cell.2016.10.028

160. Liu, Y., Petrovic, A., Rombaut, P., Mosalaganti, S., Keller, J., Raunser, S., Herzog, F., Musacchio, A.: Insights from the reconstitution of the divergent outer kinetochore of Drosophila melanogaster. Open Biol. 6, 150236 (2016). doi:10.1098/rsob.150236

161. Vijayvargia, R., Epand, R., Leitner, A., Jung, T.-Y., Shin, B., Jung, R., Lloret, A., Atwal, R.S., Lee, H., Lee, J.-M., Aebersold, R., Hebert, H., Song, J.-J., Seong, I.S.: Huntingtin's spherical solenoid structure enables polyglutamine tract-dependent modulation of its structure and function. Elife. 5, e11184 (2016). doi:10.7554/eLife.11184 
162. Armony, G., Jacob, E., Moran, T., Levin, Y., Mehlman, T., Levy, Y., Fass, D.: Crosslinking reveals laminin coiled-coil architecture. Proc. Natl. Acad. Sci. U.S.A. 113, 1338413389 (2016). doi:10.1073/pnas.1608424113

163. Thierry, E., Guilligay, D., Kosinski, J., Bock, T., Gaudon, S., Round, A., Pflug, A., Hengrung, N., Omari, K. El, Baudin, F., Hart, D.J., Beck, M., Cusack, S.: Influenza Polymerase Can Adopt an Alternative Configuration Involving a Radical Repacking of PB2 Domains. Mol. Cell. 61, 125-137 (2016). doi:10.1016/j.molcel.2015.11.016

164. Legal, T., Zou, J., Sochaj, A., Rappsilber, J., Welburn, J.P.I.: Molecular architecture of the Dam1 complex-microtubule interaction. Open Biol. 6, (2016). doi:10.1098/rsob.150237

165. Bosse, K., Haneder, S., Arlt, C., Ihling, C.H., Seufferlein, T., Sinz, A.: Mass spectrometry-based secretome analysis of non-small cell lung cancer cell lines. Proteomics. 16, 2801-2814 (2016). doi:10.1002/pmic.201600297

166. Robinson, P.J., Trnka, M.J., Bushnell, D.A., Davis, R.E., Mattei, P.J., Burlingame, A.L., Kornberg, R.D.: Structure of a Complete Mediator-RNA Polymerase II Pre-Initiation Complex. Cell. 166, 1411-1422 (2016). doi:10.1016/j.cell.2016.08.050

167. Deblasio, S.L., Chavez, J.D., Alexander, M.M., Ramsey, J., Eng, J.K., Mahoney, J., Gray, S.M., Bruce, J.E., Cilia, M.: Visualization of Host-Polerovirus Interaction Topologies Using Protein Interaction Reporter Technology. (2016). doi:10.1128/JVI.01706-15

168. Wu, X., Chavez, J.D., Schweppe, D.K., Zheng, C., Weisbrod, C.R., Eng, J.K., Murali, A., Lee, S.A., Ramage, E., Gallagher, L.A., Kulasekara, H.D., Edrozo, M.E., Kamischke, C.N., Brittnacher, M.J., Miller, S.I., Singh, P.K., Manoil, C., Bruce, J.E.: In vivo protein interaction network analysis reveals porin-localized antibiotic inactivation in Acinetobacter baumannii strain AB5075. Nat. Commun. 7, 13414 (2016). doi:10.1038/ncomms 13414

169. Gutierrez, C.B., Yu, C., Novitsky, E.J., Huszagh, A.S., Rychnovsky, S.D., Huang, L.: Developing an acidic residue reactive and sulfoxide-containing MS-cleavable homobifunctional cross-linker for probing protein-protein interactions. Anal. Chem. 88, 8315-8322 (2016). doi:10.1021/acs.analchem.6b02240

170. Chakrabarty, J.K., Naik, A.G., Fessler, M.B., Munske, G.R., Chowdhury, S.M.: Differential Tandem Mass Spectrometry-Based Cross-Linker: A New Approach for High Confidence in Identifying Protein Cross-Linking. Anal. Chem. 88, 10215-10222 (2016). doi:10.1021/acs.analchem.6b02886

171. Groitl, B., Horowitz, S., Makepeace, K.A.T., Petrotchenko, E. V., Borchers, C.H., Reichmann, D., Bardwell, J.C.A., Jakob, U.: Protein unfolding as a switch from selfrecognition to high-affinity client binding. Nat. Commun. (2016). doi:10.1038/ncomms 10357 
172. Kosinski, J., Mosalaganti, S., von Appen, A., Teimer, R., DiGuilio, A.L., Wan, W., Bui, K.H., Hagen, W.J.H.H., Briggs, J.A.G.G., Glavy, J.S., Hurt, E., Beck, M.: Molecular architecture of the inner ring scaffold of the human nuclear pore complex. Science (80-. ). 352, 363-365 (2016). doi:10.1126/science.aaf0643

173. Tan, D., Zhang, P., Ding, Y.-H., Tao, L., Dong, M.-Q., Li, Q., Zhang, M.-J., Yang, B., Li, X., Ma, S., Liu, X., Ye, K., Lei, X., Liu, C., Fan, S.-B., He, S.-M., Ma, C., Liu, J., Feng, B., Wang, H.-W., Gao, N., Zhang, P., Ding, Y.-H., Fan, S.-B., Tao, L., Yang, B., Li, X., Ma, S., Liu, J., Feng, B., Liu, X., Wang, H.-W., He, S.-M., Gao, N., Ye, K., Dong, M.-Q., Lei, X.: Trifunctional cross-linker for mapping protein-protein interaction networks and comparing protein conformational states. Elife. 5, (2016). doi:10.7554/eLife.12509

174. Dauden, M.I., Kosinski, J., Kolaj-Robin, O., Desfosses, A., Ori, A., Faux, C., Hoffmann, N.A., Onuma, O.F., Breunig, K.D., Beck, M., Sachse, C., Séraphin, B., Glatt, S., Müller, C.W.: Architecture of the yeast Elongator complex. EMBO Rep. 18, 264-279 (2017). doi:10.15252/embr.201643353

175. Ostan, N.K.H., Yu, R.-H., Ng, D., Lai, C.C.-L., Pogoutse, A.K., Sarpe, V., Hepburn, M., Sheff, J., Raval, S., Schriemer, D.C., Moraes, T.F., Schryvers, A.B.: Lactoferrin binding protein B - a bi-functional bacterial receptor protein. PLoS Pathog. 13, e1006244 (2017). doi:10.1371/journal.ppat.1006244

176. Wang, X., Chemmama, I.E., Yu, C., Huszagh, A., Xu, Y., Viner, R., Block, S.A., Cimermancic, P., Rychnovsky, S.D., Ye, Y., Sali, A., Huang, L.: The proteasomeinteracting Ecm29 protein disassembles the 26S proteasome in response to oxidative stress. J. Biol. Chem. 292, 16310-16320 (2017). doi:10.1074/jbc.M117.803619

177. Stjepanovic, G., Baskaran, S., Lin, M.G., Hurley, J.H.: Vps34 Kinase Domain Dynamics Regulate the Autophagic PI 3-Kinase Complex. Mol. Cell. 67, 528-534.e3 (2017). doi:10.1016/j.molcel.2017.07.003

178. Kim, J.O., Zelter, A., Umbreit, N.T., Bollozos, A., Riffle, M., Johnson, R., MacCoss, M.J., Asbury, C.L., Davis, T.N.: The Ndc80 complex bridges two Dam1 complex rings. Elife. 6, (2017). doi:10.7554/eLife.21069

179. Barandun, J., Chaker-Margot, M., Hunziker, M., Molloy, K.R., Chait, B.T., Klinge, S.: The complete structure of the small-subunit processome. Nat. Struct. Mol. Biol. 24, 944953 (2017). doi:10.1038/nsmb.3472

180. Hillen, H.S., Parshin, A. V, Agaronyan, K., Morozov, Y.I., Graber, J.J., Chernev, A., Schwinghammer, K., Urlaub, H., Anikin, M., Cramer, P., Temiakov, D.: Mechanism of Transcription Anti-termination in Human Mitochondria. Cell. 171, 1082-1093.e13 (2017). doi:10.1016/j.cell.2017.09.035 
181. Henning, L.M., Santos, K.F., Sticht, J., Jehle, S., Lee, C.-T., Wittwer, M., Urlaub, H., Stelzl, U., Wahl, M.C., Freund, C.: A new role for FBP21 as regulator of Brr2 helicase activity. Nucleic Acids Res. 45, $7922-7937$ (2017). doi:10.1093/nar/gkx535

182. Scacioc, A., Schmidt, C., Hofmann, T., Urlaub, H., Kühnel, K., Pérez-Lara, Á.: Structure based biophysical characterization of the PROPPIN Atg18 shows Atg18 oligomerization upon membrane binding. Sci Rep. 7, 14008 (2017). doi:10.1038/s41598-017-14337-5

183. Sen, P., Luo, J., Hada, A., Hailu, S.G., Dechassa, M.L., Persinger, J., Brahma, S., Paul, S., Ranish, J., Bartholomew, B.: Loss of Snf5 Induces Formation of an Aberrant SWI/SNF Complex. Cell Rep. 18, 2135-2147 (2017). doi:10.1016/j.celrep.2017.02.017

184. Arlt, C., Flegler, V., Ihling, C.H., Schäfer, M., Thondorf, I., Sinz, A.: An Integrated Mass Spectrometry Based Approach to Probe the Structure of the Full-Length Wild-Type Tetrameric p53 Tumor Suppressor. Angew. Chem. Int. Ed. Engl. 56, 275-279 (2017). doi:10.1002/anie.201609826

185. Xu, Y., Bernecky, C., Lee, C.-T., Maier, K.C., Schwalb, B., Tegunov, D., Plitzko, J.M., Urlaub, H., Cramer, P.: Architecture of the RNA polymerase II-Paf1C-TFIIS transcription elongation complex. Nat Commun. 8, 15741 (2017). doi:10.1038/ncomms15741

186. Liu, T., Dai, A., Cao, Y., Zhang, R., Dong, M.-Q., Wang, H.-W.: Structural Insights of WHAMM's Interaction with Microtubules by Cryo-EM. J. Mol. Biol. 429, 1352-1363 (2017). doi:10.1016/j.jmb.2017.03.022

187. Fagerlund, R.D., Wilkinson, M.E., Klykov, O., Barendregt, A., Pearce, F.G., Kieper, S.N., Maxwell, H.W.R., Capolupo, A., Heck, A.J.R., Krause, K.L., Bostina, M., Scheltema, R.A., Staals, R.H.J., Fineran, P.C.: Spacer capture and integration by a type I-F Cas1Cas2-3 CRISPR adaptation complex. Proc. Natl. Acad. Sci. U.S.A. 114, E5122-E5128 (2017). doi:10.1073/pnas.1618421114

188. Said, N., Krupp, F., Anedchenko, E., Santos, K.F., Dybkov, O., Huang, Y.-H., Lee, C.-T., Loll, B., Behrmann, E., Bürger, J., Mielke, T., Loerke, J., Urlaub, H., Spahn, C.M.T., Weber, G., Wahl, M.C.: Structural basis for $\lambda \mathrm{N}$-dependent processive transcription antitermination. Nat Microbiol. 2, 17062 (2017). doi:10.1038/nmicrobiol.2017.62

189. Bertram, K., Agafonov, D.E., Dybkov, O., Haselbach, D., Leelaram, M.N., Will, C.L., Urlaub, H., Kastner, B., Lührmann, R., Stark, H.: Cryo-EM Structure of a Pre-catalytic Human Spliceosome Primed for Activation. Cell. 170, 701-713.e11 (2017). doi:10.1016/j.cell.2017.07.011

190. Rivera-Santiago, R., Harper, S.L., Sriswasdi, S., Hembach, P., Speicher, D.W.: FullLength Anion Exchanger 1 Structure and Interactions with Ankyrin-1 Determined by Zero Length Crosslinking of Erythrocyte Membranes. Structure. 25, 132-145 (2017). doi:10.1016/j.str.2016.11.017 
191. Bhat, J.Y., Miličić, G., Thieulin-Pardo, G., Bracher, A., Maxwell, A., Ciniawsky, S., Mueller-Cajar, O., Engen, J.R., Hartl, F.U., Wendler, P., Hayer-Hartl, M.: Mechanism of Enzyme Repair by the AAA+ Chaperone Rubisco Activase. Mol. Cell. 67, 744-756.e6 (2017). doi:10.1016/j.molcel.2017.07.004

192. Lehmann, L.C., Hewitt, G., Aibara, S., Leitner, A., Marklund, E., Maslen, S.L., Maturi, V., Chen, Y., van der Spoel, D., Skehel, J.M., Moustakas, A., Boulton, S.J., Deindl, S.: Mechanistic Insights into Autoinhibition of the Oncogenic Chromatin Remodeler ALC1. Mol. Cell. 68, 847-859.e7 (2017). doi:10.1016/j.molcel.2017.10.017

193. Böttcher, R.T., Veelders, M., Rombaut, P., Faix, J., Theodosiou, M., Stradal, T.E., Rottner, K., Zent, R., Herzog, F., Fässler, R.: Kindlin-2 recruits paxillin and Arp2/3 to promote membrane protrusions during initial cell spreading. J. Cell Biol. 216, 3785-3798 (2017). doi:10.1083/jcb.201701176

194. Bertram, K., Agafonov, D.E., Liu, W.-T., Dybkov, O., Will, C.L., Hartmuth, K., Urlaub, H., Kastner, B., Stark, H., Lührmann, R.: Cryo-EM structure of a human spliceosome activated for step 2 of splicing. Nature. 542, 318-323 (2017). doi:10.1038/nature21079

195. Scott, H., Kim, J.-K., Yu, C., Huang, L., Qiao, F., Taylor, D.J.: Spatial Organization and Molecular Interactions of the Schizosaccharomyces pombe Ccq1-Tpz1-Poz1 Shelterin Complex. J. Mol. Biol. 429, 2863-2872 (2017). doi:10.1016/j.jmb.2017.08.002

196. Zhou, C.Y., Stoddard, C.I., Johnston, J.B., Trnka, M.J., Echeverria, I., Palovcak, E., Sali, A., Burlingame, A.L., Cheng, Y., Narlikar, G.J.: Regulation of Rvb1/Rvb2 by a Domain within the INO80 Chromatin Remodeling Complex Implicates the Yeast Rvbs as Protein Assembly Chaperones. Cell Rep. 19, 2033-2044 (2017). doi:10.1016/j.celrep.2017.05.029

197. Ledbetter, R.N., Costas, A.M.G., Lubner, C.E., Mulder, D.W., Tokmina-Lukaszewska, M., Artz, J.H., Patterson, A., Magnuson, T.S., Jay, Z.J., Duan, H.D., Miller, J., Plunkett, M.H., Hoben, J.P., Barney, B.M., Carlson, R.P., Miller, A.-F., Bothner, B., King, P.W., Peters, J.W., Seefeldt, L.C.: The Electron Bifurcating FixABCX Protein Complex from Azotobacter vinelandii: Generation of Low-Potential Reducing Equivalents for $\begin{array}{lllll}\text { Nitrogenase } \quad \text { Catalysis. } & \text { Biochemistry. }\end{array}$ doi:10.1021/acs.biochem.7b00389

198. Patel, N., Stengel, F., Aebersold, R., Gold, M.G.: Molecular basis of AKAP79 regulation by calmodulin. Nat. Commun. 8, 1681 (2017). doi:10.1038/s41467-017-01715-w

199. Ye, Q., Kim, D.H., Dereli, I., Rosenberg, S.C., Hagemann, G., Herzog, F., Tóth, A., Cleveland, D.W., Corbett, K.D.: The AAA+ ATPase TRIP13 remodels HORMA domains through N-terminal engagement and unfolding. EMBO J. 36, 2419-2434 (2017). doi:10.15252/embj.201797291 
200. Sadian, Y., Tafur, L., Kosinski, J., Jakobi, A.J., Wetzel, R., Buczak, K., Hagen, W.J., Beck, M., Sachse, C., Müller, C.W.: Structural insights into transcription initiation by yeast RNA polymerase I. EMBO J. 36, 2698-2709 (2017). doi:10.15252/embj.201796958

201. de Jong, L., de Koning, E.A., Roseboom, W., Buncherd, H., Wanner, M.J., Dapic, I., Jansen, P.J., van Maarseveen, J.H., Corthals, G.L., Lewis, P.J., Hamoen, L.W., de Koster, C.G.: In-Culture Cross-Linking of Bacterial Cells Reveals Large-Scale Dynamic ProteinProtein Interactions at the Peptide Level. J. Proteome Res. 16, 2457-2471 (2017). doi:10.1021/acs.jproteome.7b00068

202. Hage, C., Iacobucci, C., Rehkamp, A., Arlt, C., Sinz, A.: The First Zero-Length Mass Spectrometry-Cleavable Cross-Linker for Protein Structure Analysis. Angew. Chem. Int. Ed. Engl. 56, 14551-14555 (2017). doi:10.1002/anie.201708273

203. Schmidt, C., Beilsten-Edmands, V., Mohammed, S., Robinson, C. V: Acetylation and phosphorylation control both local and global stability of the chloroplast F1 ATP synthase. Sci Rep. 7, 44068 (2017). doi:10.1038/srep44068

204. Komolov, K.E., Du, Y., Duc, N.M., Betz, R.M., Rodrigues, J.P.G.L.M., Leib, R.D., Patra, D., Skiniotis, G., Adams, C.M., Dror, R.O., Chung, K.Y., Kobilka, B.K., Benovic, J.L.: Structural and Functional Analysis of a $\beta 2$-Adrenergic Receptor Complex with GRK5. Cell. 169, 407-421.e16 (2017)

205. Chen, J.W.C., Chen, Z.A., Rogala, K.B., Metz, J., Deane, C.M., Rappsilber, J., Wakefield, J.G.: Cross-linking mass spectrometry identifies new interfaces of Augmin required to localise the $\gamma$-tubulin ring complex to the mitotic spindle. Biol. Open. 6, 654-663 (2017)

206. Yuan, Z., Riera, A., Bai, L., Sun, J., Nandi, S., Spanos, C., Chen, Z.A., Barbon, M., Rappsilber, J., Stillman, B., Speck, C., Li, H.: Structural basis of Mcm2-7 replicative helicase loading by ORC-Cdc6 and Cdt1. Nat. Struct. Mol. Biol. 24, 316-324 (2017)

207. Walker-Gray, R., Stengel, F., Gold, M.G.: Mechanisms for restraining cAMP-dependent protein kinase revealed by subunit quantitation and cross-linking approaches. Proc. Natl. Acad. Sci. U. S. A. 114, 10414-10419 (2017)

208. Iacobucci, C., Hage, C., Schäfer, M., Sinz, A.: A Novel MS-Cleavable Azo Cross-Linker for Peptide Structure Analysis by Free Radical Initiated Peptide Sequencing (FRIPS). J. Am. Soc. Mass Spectrom. 28, 2039-2053 (2017). doi:10.1007/s13361-017-1744-6

209. Debelyy, M.O., Waridel, P., Quadroni, M., Schneiter, R., Conzelmann, A.: Chemical crosslinking and mass spectrometry to elucidate the topology of integral membrane proteins. PLoS One. 12, e0186840 (2017)

210. Weisz, D.A., Liu, H., Zhang, H., Thangapandian, S., Tajkhorshid, E., Gross, M.L., Pakrasi, H.B.: Mass spectrometry-based cross-linking study shows that the Psb28 protein 
binds to cytochrome b559 in Photosystem II. Proc. Natl. Acad. Sci. U.S.A. 114, 22242229 (2017). doi:10.1073/pnas. 1620360114

211. Blees, A., Januliene, D., Hofmann, T., Koller, N., Schmidt, C., Trowitzsch, S., Moeller, A., Robert Tampé, \&: Structure of the human MHC-I peptide-loading complex. (2017)

212. Mosalaganti, S., Keller, J., Altenfeld, A., Winzker, M., Rombaut, P., Saur, M., Petrovic, A., Wehenkel, A., Wohlgemuth, S., Müller, F., Maffini, S., Bange, T., Herzog, F., Waldmann, H., Raunser, S., Musacchio, A.: Structure of the RZZ complex and molecular basis of its interaction with Spindly. J. Cell Biol. 216, 961-981 (2017)

213. Liu, Q., Remmelzwaal, S., Heck, A.J.R., Akhmanova, A., Liu, F.: Facilitating identification of minimal protein binding domains by cross-linking mass spectrometry. Sci. Rep. 7, (2017). doi:10.1038/s41598-017-13663-y

214. Gupta, K., Watson, A.A., Baptista, T., Scheer, E., Chambers, A.L., Koehler, C., Zou, J., Obong-Ebong, I., Kandiah, E., Temblador, A., Round, A., Forest, E., Man, P., Bieniossek, C., Laue, E.D., Lemke, E.A., Rappsilber, J., Robinson, C. V, Devys, D., Tora, L., Berger, I.: Architecture of TAF11/TAF13/TBP complex suggests novel regulation properties of general transcription factor TFIID. Elife. 6, (2017). doi:10.7554/eLife.30395

215. Zhong, X., Navare, A.T., Chavez, J.D., Eng, J.K., Schweppe, D.K., Bruce, J.E.: LargeScale and Targeted Quantitative Cross-Linking MS Using Isotope-Labeled Protein Interaction Reporter (PIR) Cross-Linkers. J. Proteome Res. 16, 720-727 (2017). doi:10.1021/acs.jproteome.6b00752

216. Kastritis, P.L., O’Reilly, F.J., Bock, T., Li, Y., Rogon, M.Z., Buczak, K., Romanov, N., Betts, M.J., Bui, K.H., Hagen, W.J., Hennrich, M.L., Mackmull, M., Rappsilber, J., Russell, R.B., Bork, P., Beck, M., Gavin, A.: Capturing protein communities by structural proteomics in a thermophilic eukaryote. Mol. Syst. Biol. 13, 936 (2017)

217. Wang, X., Cimermancic, P., Yu, C., Schweitzer, A., Chopra, N., Engel, J.L., Greenberg, C., Huszagh, A.S., Beck, F., Sakata, E., Yang, Y., Novitsky, E.J., Leitner, A., Nanni, P., Kahraman, A., Guo, X., Dixon, J.E., Rychnovsky, S.D., Aebersold, R., Baumeister, W., Sali, A., Huang, L.: Molecular Details Underlying Dynamic Structures and Regulation of the Human 26S Proteasome. Mol. Cell. Proteomics. 16, 840-854 (2017). doi:10.1074/mcp.M116.065326

218. Schweppe, D.D.K.D., Chavez, J.D.J., Lee, C.C.F., Caudal, A., Kruse, S.S.E., Stuppard, R., Marcinek, D.D.J.D., Shadel, G.G.S., Tian, R., Bruce, J.E.J.: Mitochondrial protein interactome elucidated by chemical cross-linking mass spectrometry. Proc. Natl. Acad. Sci. 114, 1732-1737 (2017). doi:10.1073/pnas.1617220114

219. Harrer, N., Schindler, C.E.M., Bruetzel, L.K., Forné, I., Ludwigsen, J., Imhof, A., Zacharias, M., Lipfert, J., Mueller-Planitz, F.: Structural Architecture of the Nucleosome 
Remodeler ISWI Determined from Cross-Linking, Mass Spectrometry, SAXS, and Modeling. Structure. 26, 282-294 (2018). doi:10.1016/j.str.2017.12.015

220. Martinez-Martin, N., Marcandalli, J., Huang, C.S., Arthur, C.P., Perotti, M., Foglierini, M., Ho, H., Dosey, A.M., Shriver, S., Payandeh, J., Leitner, A., Lanzavecchia, A., Perez, L., Ciferri, C.: An Unbiased Screen for Human Cytomegalovirus Identifies Neuropilin-2 as a Central Viral Receptor. Cell. 174, 1158-1171.e19 (2018). doi:10.1016/j.cell.2018.06.028

221. Luan, Q., Zelter, A., MacCoss, M.J., Davis, T.N., Nolen, B.J.: Identification of WiskottAldrich syndrome protein (WASP) binding sites on the branched actin filament nucleator Arp2/3 complex. Proc. Natl. Acad. Sci. U.S.A. 115, E1409-E1418 (2018). doi:10.1073/pnas.1716622115

222. Sanghai, Z.A., Miller, L., Molloy, K.R., Barandun, J., Hunziker, M., Chaker-Margot, M., Wang, J., Chait, B.T., Klinge, S.: Modular assembly of the nucleolar pre-60S ribosomal subunit. Nature. 556, 126-129 (2018). doi:10.1038/nature26156

223. Rehkamp, A., Tänzler, D., Iacobucci, C., Golbik, R.P., Ihling, C.H., Sinz, A.: Molecular Details of Retinal Guanylyl Cyclase 1/GCAP-2 Interaction. Front Mol Neurosci. 11, 330 (2018). doi:10.3389/fnmol.2018.00330

224. Dickmanns, A., Zschiedrich, C.P., Arens, J., Parfentev, I., Gundlach, J., Hofele, R., Neumann, P., Urlaub, H., Görke, B., Ficner, R., Stülke, J.: Structural basis for the regulatory interaction of the methylglyoxal synthase MgsA with the carbon flux regulator Crh in Bacillus subtilis . J. Biol. Chem. 293, 5781-5792 (2018). doi:10.1074/jbc.RA117.001289

225. de la Parra, C., Ernlund, A., Alard, A., Ruggles, K., Ueberheide, B., Schneider, R.J.: A widespread alternate form of cap-dependent mRNA translation initiation. Nat Commun. 9, 3068 (2018). doi:10.1038/s41467-018-05539-0

226. Martin, E.M., Jackson, M.P., Gamerdinger, M., Gense, K., Karamonos, T.K., Humes, J.R., Deuerling, E., Ashcroft, A.E., Radford, S.E.: Conformational flexibility within the nascent polypeptide-associated complex enables its interactions with structurally diverse client proteins. J. Biol. Chem. 293, 8554-8568 (2018). doi:10.1074/jbc.RA117.001568

227. Yoon, J., Kim, S.J., An, S., Cho, S., Leitner, A., Jung, T., Aebersold, R., Hebert, H., Cho, U.-S., Song, J.-J.: Integrative Structural Investigation on the Architecture of Human Importin4_Histone H3/H4_Asfla Complex and Its Histone H3 Tail Binding. J. Mol. Biol. 430, 822-841 (2018). doi: $10.1016 /$ j.jmb.2018.01.015

228. Zheng, J., Corzo, C., Chang, M.R., Shang, J., Lam, V.Q., Brust, R., Blayo, A.-L., Bruning, J.B., Kamenecka, T.M., Kojetin, D.J., Griffin, P.R.: Chemical Crosslinking Mass Spectrometry Reveals the Conformational Landscape of the Activation Helix of PPAR $\gamma$; a 
Model for Ligand-Dependent Antagonism. Structure. 26, 1431-1439.e6 (2018). doi:10.1016/j.str.2018.07.007

229. Bleichert, F., Leitner, A., Aebersold, R., Botchan, M.R., Berger, J.M.: Conformational control and DNA-binding mechanism of the metazoan origin recognition complex. Proc. Natl. Acad. Sci. U.S.A. 115, E5906-E5915 (2018). doi:10.1073/pnas.1806315115

230. Rega, C., Russo, R., Focà, A., Sandomenico, A., Iaccarino, E., Raimondo, D., Milanetti, E., Tornatore, L., Franzoso, G., Pedone, P.V., Ruvo, M., Chambery, A.: Probing the interaction interface of the GADD45 $\beta /$ MKK7 and MKK7/DTP3 complexes by chemical cross-linking mass spectrometry. Int. J. Biol. Macromol. 114, 114-123 (2018). doi:10.1016/j.ijbiomac.2018.03.090

231. Horne, J.E., Walko, M., Calabrese, A.N., Levenstein, M.A., Brockwell, D.J., Kapur, N., Wilson, A.J., Radford, S.E.: Rapid Mapping of Protein Interactions Using Tag-Transfer Photocrosslinkers. Angew. Chem. Int. Ed. Engl. 57, $16688-16692$ (2018). doi:10.1002/anie.201809149

232. Kuhlen, L., Abrusci, P., Johnson, S., Gault, J., Deme, J., Caesar, J., Dietsche, T., Mebrhatu, M.T., Ganief, T., Macek, B., Wagner, S., Robinson, C. V, Lea, S.M.: Structure of the core of the type III secretion system export apparatus. Nat. Struct. Mol. Biol. 25, 583-590 (2018). doi:10.1038/s41594-018-0086-9

233. Zhou, J., Yang, L., Ozohanics, O., Zhang, X., Wang, J., Ambrus, A., Arjunan, P., Brukh, R., Nemeria, N.S., Furey, W., Jordan, F.: A multipronged approach unravels unprecedented protein-protein interactions in the human 2-oxoglutarate dehydrogenase multienzyme complex. J. Biol. Chem. 293, 19213-19227 (2018). doi:10.1074/jbc.RA118.005432

234. Vos, S.M., Farnung, L., Boehning, M., Wigge, C., Linden, A., Urlaub, H., Cramer, P.: Structure of activated transcription complex Pol II-DSIF-PAF-SPT6. Nature. 560, 607612 (2018). doi:10.1038/s41586-018-0440-4

235. Haselbach, D., Komarov, I., Agafonov, D.E., Hartmuth, K., Graf, B., Dybkov, O., Urlaub, H., Kastner, B., Lührmann, R., Stark, H.: Structure and Conformational Dynamics of the Human Spliceosomal Bact Complex. Cell. 172, 454-464.e11 (2018). doi:10.1016/j.cell.2018.01.010

236. Will, N., Lee, K., Hajredini, F., Giles, D.H., Abzalimov, R.R., Clarkson, M., Dalby, K.N., Ghose, R.: Structural Dynamics of the Activation of Elongation Factor 2 Kinase by Ca2+Calmodulin. J. Mol. Biol. 430, 2802-2821 (2018). doi:10.1016/j.jmb.2018.05.033

237. Myers, J.B., Haddad, B.G., O’Neill, S.E., Chorev, D.S., Yoshioka, C.C., Robinson, C. V., Zuckerman, D.M., Reichow, S.L.: Structure of native lens connexin 46/50 intercellular channels by cryo-EM. Nature. 564, 372-377 (2018) 
238. Bräuning, B., Bertosin, E., Praetorius, F., Ihling, C., Schatt, A., Adler, A., Richter, K., Sinz, A., Dietz, H., Groll, M.: Structure and mechanism of the two-component $\alpha$-helical pore-forming toxin YaxAB. Nat Commun. 9, 1806 (2018). doi:10.1038/s41467-01804139-2

239. Mei, K., Li, Y., Wang, S., Shao, G., Wang, J., Ding, Y., Luo, G., Yue, P., Liu, J.-J., Wang, X., Dong, M.-Q., Wang, H.-W., Guo, W.: Cryo-EM structure of the exocyst complex. Nat. Struct. Mol. Biol. 25, 139-146 (2018). doi:10.1038/s41594-017-0016-2

240. Cai, K., Frederick, R.O., Dashti, H., Markley, J.L.: Architectural Features of Human Mitochondrial Cysteine Desulfurase Complexes from Crosslinking Mass Spectrometry and Small-Angle X-Ray Scattering. Structure. 26, 1127-1136.e4 (2018). doi:10.1016/j.str.2018.05.017

241. Vos, S.M., Farnung, L., Urlaub, H., Cramer, P.: Structure of paused transcription complex Pol II-DSIF-NELF. Nature. 560, 601-606 (2018). doi:10.1038/s41586-018-0442-2

242. Eliseev, B., Yeramala, L., Leitner, A., Karuppasamy, M., Raimondeau, E., Huard, K., Alkalaeva, E., Aebersold, R., Schaffitzel, C.: Structure of a human cap-dependent 48S translation pre-initiation complex. Nucleic Acids Res. 46, 2678-2689 (2018). doi:10.1093/nar/gky054

243. Söderberg, C.A.G., Månsson, C., Bernfur, K., Rutsdottir, G., Härmark, J., Rajan, S., AlKaradaghi, S., Rasmussen, M., Höjrup, P., Hebert, H., Emanuelsson, C.: Structural modelling of the DNAJB6 oligomeric chaperone shows a peptide-binding cleft lined with conserved S/T-residues at the dimer interface. Sci Rep. 8, 5199 (2018). doi:10.1038/s41598-018-23035-9

244. Gamarra, N., Johnson, S.L., Trnka, M.J., Burlingame, A.L., Narlikar, G.J.: The nucleosomal acidic patch relieves auto-inhibition by the ISWI remodeler SNF2h. Elife. 7, (2018). doi:10.7554/eLife.35322

245. Chowdhury, S., Otomo, C., Leitner, A., Ohashi, K., Aebersold, R., Lander, G.C., Otomo, T.: Insights into autophagosome biogenesis from structural and biochemical analyses of the ATG2A-WIPI4 complex. Proc. Natl. Acad. Sci. U.S.A. 115, E9792-E9801 (2018). doi:10.1073/pnas.1811874115

246. Helgeson, L.A., Zelter, A., Riffle, M., MacCoss, M.J., Asbury, C.L., Davis, T.N.: Human Ska complex and Ndc80 complex interact to form a load-bearing assembly that strengthens kinetochore-microtubule attachments. Proc. Natl. Acad. Sci. U.S.A. 115, 2740-2745 (2018). doi:10.1073/pnas.1718553115

247. Henry, N., Krammer, E.-M., Stengel, F., Adams, Q., Van Liefferinge, F., Hubin, E., Chaves, R., Efremov, R., Aebersold, R., Vandenbussche, G., Prévost, M., Raussens, V., Deroo, S.: Lipidated apolipoprotein E4 structure and its receptor binding mechanism 
determined by a combined cross-linking coupled to mass spectrometry and molecular dynamics approach. PLOS Comput. Biol. 14, e1006165 (2018)

248. Oroz, J., Chang, B.J., Wysoczanski, P., Lee, C.-T., Pérez-Lara, Á., Chakraborty, P., Hofele, R. V., Baker, J.D., Blair, L.J., Biernat, J., Urlaub, H., Mandelkow, E., Dickey, C.A., Zweckstetter, M.: Structure and pro-toxic mechanism of the human Hsp90/PPIase/Tau complex. Nat. Commun. 9, 4532 (2018)

249. Schäfer, P., Tüting, C., Schönemann, L., Kühn, U., Treiber, T., Treiber, N., Ihling, C., Graber, A., Keller, W., Meister, G., Sinz, A., Wahle, E.: Reconstitution of mammalian cleavage factor II involved in $3^{\prime}$ processing of mRNA precursors. RNA. (2018). doi:10.1261/rna.068056.118

250. Liu, F., Lössl, P., Rabbitts, B., Balaban, R., Heck, A.: The interactome of intact mitochondria by cross-linking mass spectrometry provides evidence for coexisting respiratory supercomplexes. Mol. Cell. proteomics. 17, 216-232 (2018)

251. Schütz, S., Michel, E., Damberger, F.F., Oplová, M., Peña, C., Leitner, A., Aebersold, R., Allain, F.H.-T., Panse, V.G.: Molecular basis for disassembly of an importin:ribosomal protein complex by the escortin Tsr2. Nat. Commun. 9, 3669 (2018). doi:10.1038/s41467018-06160-x

252. Sailer, C., Offensperger, F., Julier, A., Kammer, K.-M., Walker-Gray, R., Gold, M.G., Scheffner, M., Stengel, F.: Structural dynamics of the E6AP/UBE3A-E6-p53 enzymesubstrate complex. Nat. Commun. 9, 4441 (2018)

253. Liu, S., Yu, F., Hu, Q., Wang, T., Yu, L., Du, S., Yu, W., Li, N.: Development of in Planta Chemical Cross-Linking-Based Quantitative Interactomics in Arabidopsis. J. Proteome Res. 17, 3195-3213 (2018). doi:10.1021/acs.jproteome.8b00320

254. Fasci, D., van Ingen, H., Scheltema, R.A., Heck, A.J.R.: Histone Interaction Landscapes Visualized by Crosslinking Mass Spectrometry in Intact Cell Nuclei. Mol. Cell. Proteomics. 17, 2018-2033 (2018). doi:10.1074/mcp.ra118.000924

255. Jishage, M., Yu, X., Shi, Y., Ganesan, S.J., Chen, W.Y., Sali, A., Chait, B.T., Asturias, F.J., Roeder, R.G.: Architecture of Pol II(G) and molecular mechanism of transcription regulation by Gdown1. Nat. Struct. Mol. Biol. 25, 859-867 (2018). doi:10.1038/s41594018-0118-5

256. Gutierrez, C.B., Block, S.A., Yu, C., Soohoo, S.M., Huszagh, A.S., Rychnovsky, S.D., Huang, L.: Development of a Novel Sulfoxide-Containing MS-Cleavable Homobifunctional Cysteine-Reactive Cross-Linker for Studying Protein-Protein Interactions. Anal. Chem. 90, 7600-7607 (2018). doi:10.1021/acs.analchem.8b01287

257. Smith, D.-L.L., Götze, M., Bartolec, T.K., Hart-Smith, G., Wilkins, M.R.: Characterization of the Interaction between Arginine Methyltransferase Hmtl and Its 
Substrate Np13: Use of Multiple Cross-Linkers, Mass Spectrometric Approaches, and $\begin{array}{llllll}\text { Software Platforms. Anal. Chem. 90, 9101-9108 (2018). } & \end{array}$ doi:10.1021/acs.analchem. 8 b01525

258. Yu, Z., Jarrold, M.F., Williams, R., Ludtke, S.J., Echeverria, I., Slaughter, B.D., Chemmama, I.E., Unruh, J.R., Mironska, R., De La Cruz, M.J., Hogan, J.A., Shivaraju, M., Chaudhury, A.S., Raveh, B., Wang, J., Pellarin, R., Upla, P., Kim, S.J., Herricks, T., Nudelman, I., Sali, A., Zhang, W., Stokes, D.L., Aitchison, J.D., Rout, M.P., Shi, Y., Akey, C.W., Greenberg, C.H., Fernandez-Martinez, J., Chait, B.T., Gerton, J.L., Jacobs, E.Y., Nudelman, I., Shi, Y., Zhang, W., Raveh, B., Herricks, T., Slaughter, B.D., Hogan, J.A., Upla, P., Chemmama, I.E., Pellarin, R., Echeverria, I., Shivaraju, M., Chaudhury, A.S., Wang, J., Williams, R., Unruh, J.R., Greenberg, C.H., Jacobs, E.Y., Yu, Z., De La Cruz, M.J., Mironska, R., Stokes, D.L., Aitchison, J.D., Jarrold, M.F., Gerton, J.L., Ludtke, S.J., Akey, C.W., Chait, B.T., Sali, A., Rout, M.P.: Integrative structure and functional anatomy of a nuclear pore complex. Nature. 555, 475-482 (2018). doi:10.1038/nature26003

259. Chavez, J.D., Lee, C.F., Caudal, A., Keller, A., Tian, R., Bruce, J.E.: Chemical Crosslinking Mass Spectrometry Analysis of Protein Conformations and Supercomplexes in Heart Tissue. Cell Syst. 6, 136-141 (2018). doi:10.1016/j.cels.2017.10.017

260. Quintana-Gallardo, L., Martín-Benito, J., Marcilla, M., Espadas, G., Sabidó, E., Valpuesta, J.M.: The cochaperone CHIP marks Hsp70- and Hsp90-bound substrates for degradation through a very flexible mechanism. Sci Rep. 9, 5102 (2019). doi:10.1038/s41598-019-41060-0

261. Prajapati, S., Haselbach, D., Wittig, S., Patel, M.S., Chari, A., Schmidt, C., Stark, H., Tittmann, K.: Structural and Functional Analyses of the Human PDH Complex Suggest a "Division-of-Labor" Mechanism by Local E1 and E3 Clusters. Structure. 27, 11241136.e4 (2019). doi:10.1016/j.str.2019.04.009

262. Brodie, N.I., Popov, K.I., Petrotchenko, E. V, Dokholyan, N. V, Borchers, C.H.: Conformational ensemble of native $\alpha$-synuclein in solution as determined by shortdistance crosslinking constraint-guided discrete molecular dynamics simulations. PLoS Comput. Biol. 15, e1006859 (2019). doi:10.1371/journal.pcbi.1006859

263. Farmer, D.A., Brindley, A.A., Hitchcock, A., Jackson, P.J., Johnson, B., Dickman, M.J., Hunter, C.N., Reid, J.D., Adams, N.B.P.: The ChlD subunit links the motor and porphyrin binding subunits of magnesium chelatase. Biochem. J. 476, 1875-1887 (2019). doi:10.1042/BCJ20190095

264. Hauri, S., Khakzad, H., Happonen, L., Teleman, J., Malmström, J., Malmström, L.: Rapid determination of quaternary protein structures in complex biological samples. Nat Commun. 10, 192 (2019). doi:10.1038/s41467-018-07986-1 
265. Ziemianowicz, D.S., Ng, D., Schryvers, A.B., Schriemer, D.C.: Photo-Cross-Linking Mass Spectrometry and Integrative Modeling Enables Rapid Screening of Antigen Interactions Involving Bacterial Transferrin Receptors. J. Proteome Res. 18, 934-946 (2019). doi:10.1021/acs.jproteome.8b00629

266. Mirzakhanyan, Y., Gershon, P.: The Vaccinia virion: Filling the gap between atomic and ultrastructure. PLoS Pathog. 15, e1007508 (2019). doi:10.1371/journal.ppat.1007508

267. Srivastava, D., Gakhar, L., Artemyev, N.O.: Structural underpinnings of Ric8A function as a G-protein $\alpha$-subunit chaperone and guanine-nucleotide exchange factor. Nat Commun. 10, 3084 (2019). doi:10.1038/s41467-019-11088-X

268. Luo, J., Bassett, J., Ranish, J.: Identification of Cross-linked Peptides Using Isotopomeric Cross-linkers. J. Am. Soc. Mass Spectrom. 30, 1643-1653 (2019). doi:10.1007/s13361019-02253-z

269. Hernychová, L., Rosůlek, M., Kádek, A., Mareška, V., Chmelík, J., Adámková, L., Grobárová, V., Šebesta, O., Kukačka, Z., Skála, K., Spiwok, V., Černý, J., Novák, P.: The C-type lectin-like receptor Nkrplb: Structural proteomics reveals features affecting protein conformation and interactions. J Proteomics. 196, 162-172 (2019). doi:10.1016/j.jprot.2018.11.007

270. Wu, J., Zhang, W., Xia, L., Feng, L., Shu, Z., Zhang, J., Ye, W., Zeng, N., Zhou, A.: Characterization of PPIB interaction in the P3H1 ternary complex and implications for its pathological mutations. Cell. Mol. Life Sci. (2019). doi:10.1007/s00018-019-03102-8

271. Chou, H.-T., Apelt, L., Farrell, D.P., White, S.R., Woodsmith, J., Svetlov, V., Goldstein, J.S., Nager, A.R., Li, Z., Muller, J., Dollfus, H., Nudler, E., Stelzl, U., DiMaio, F., Nachury, M. V, Walz, T.: The Molecular Architecture of Native BBSome Obtained by an Integrated Structural Approach. Structure. (2019). doi:10.1016/j.str.2019.06.006

272. McDonald, A.J., Leon, D.R., Markham, K.A., Wu, B., Heckendorf, C.F., Schilling, K., Showalter, H.D., Andrews, P.C., McComb, M.E., Pushie, M.J., Costello, C.E., Millhauser, G.L., Harris, D.A.: Altered Domain Structure of the Prion Protein Caused by $\mathrm{Cu} 2+$ Binding and Functionally Relevant Mutations: Analysis by Cross-Linking, MS/MS, and NMR. Structure. 27, 907-922.e5 (2019). doi:10.1016/j.str.2019.03.008

273. Kobayashi, W., Takizawa, Y., Aihara, M., Negishi, L., Ishii, H., Kurumizaka, H.: Structural and biochemical analyses of the nuclear pore complex component ELYS identify residues responsible for nucleosome binding. Commun Biol. 2, 163 (2019). doi:10.1038/s42003-019-0385-7

274. Longbotham, J.E., Chio, C.M., Dharmarajan, V., Trnka, M.J., Torres, I.O., Goswami, D., Ruiz, K., Burlingame, A.L., Griffin, P.R., Fujimori, D.G.: Histone H3 binding to the PHD1 domain of histone demethylase KDM5A enables active site remodeling. Nat Commun. 10, 94 (2019). doi:10.1038/s41467-018-07829-z 
275. Ivic, N., Potocnjak, M., Solis-Mezarino, V., Herzog, F., Bilokapic, S., Halic, M.: Fuzzy Interactions Form and Shape the Histone Transport Complex. Mol. Cell. 73, 1191-1203.e6 (2019)

276. Pereira, F., Rettel, M., Stein, F., Savitski, M.M., Collinson, I., Römisch, K.: Effect of Sec61 interaction with Mpd1 on endoplasmic reticulum-associated degradation. PLoS One. 14, e0211180 (2019). doi:10.1371/journal.pone.0211180

277. Colombo, M., Pessey, O., Marcia, M.: Topology and enzymatic properties of a canonical Polycomb repressive complex 1 isoform. FEBS Lett. 593, 1837-1848 (2019). doi:10.1002/1873-3468.13442

278. Kokic, G., Chernev, A., Tegunov, D., Dienemann, C., Urlaub, H., Cramer, P.: Structural basis of TFIIH activation for nucleotide excision repair. Nat Commun. 10, 2885 (2019). doi:10.1038/s41467-019-10745-5

279. West, A.M., Rosenberg, S.C., Ur, S.N., Lehmer, M.K., Ye, Q., Hagemann, G., Caballero, I., Usón, I., MacQueen, A.J., Herzog, F., Corbett, K.D.: A conserved filamentous assembly underlies the structure of the meiotic chromosome axis. Elife. 8, (2019)

280. Özcan, A., Pausch, P., Linden, A., Wulf, A., Schühle, K., Heider, J., Urlaub, H., Heimerl, T., Bange, G., Randau, L.: Type IV CRISPR RNA processing and effector complex formation in Aromatoleum aromaticum. Nat Microbiol. 4, 89-96 (2019). doi:10.1038/s41564-018-0274-8

281. Fröbel, J., Blümmel, A.-S., Drepper, F., Warscheid, B., Müller, M.: Surface-exposed domains of TatB involved in the structural and functional assembly of the Tat translocase in Escherichia coli. J. Biol. Chem. (2019). doi:10.1074/jbc.RA119.009298

282. Leong, S.L., Lynch, E.M., Zou, J., Tay, Y.D., Borek, W.E., Tuijtel, M.W., Rappsilber, J., Sawin, K.E.: Reconstitution of Microtubule Nucleation In Vitro Reveals Novel Roles for Mzt1. Curr. Biol. 29, 2199-2207.e10 (2019)

283. Fischböck-Halwachs, J., Singh, S., Potocnjak, M., Hagemann, G., Solis-Mezarino, V., Woike, S., Ghodgaonkar-Steger, M., Weissmann, F., Gallego, L.D., Rojas, J., Andreani, J., Köhler, A., Herzog, F.: The COMA complex interacts with Cse4 and positions Sli15/Ipl1 at the budding yeast inner kinetochore. Elife. 8, (2019)

284. Cardon, T., Salzet, M., Franck, J., Fournier, I.: Nuclei of HeLa cells interactomes unravel a network of ghost proteins involved in proteins translation. Biochim. Biophys. Acta Gen. Subj. 1863, 1458-1470 (2019). doi:10.1016/j.bbagen.2019.05.009

285. Zhao, B., Reilly, C.P., Reilly, J.P.: ETD-Cleavable Linker for Confident Cross-linked Peptide Identifications. J. Am. Soc. Mass Spectrom. 30, 1631-1642 (2019). doi:10.1007/s13361-019-02227-1 
286. Ser, Z., Cifani, P., Kentsis, A.: Optimized Cross-Linking Mass Spectrometry for in Situ Interaction Proteomics. J. Proteome Res. 18, 2545-2558 (2019). doi:10.1021/acs.jproteome.9b00085

287. Horn, V., Uckelmann, M., Zhang, H., Eerland, J., Aarsman, I., le Paige, U.B., Davidovich, C., Sixma, T.K., van Ingen, H.: Structural basis of specific H2A K13/K15 ubiquitination by RNF168. Nat Commun. 10, 1751 (2019). doi:10.1038/s41467-019-09756-z

288. Fux, A., Korotkov, V.S., Schneider, M., Antes, I., Sieber, S.A.: Chemical Cross-Linking Enables Drafting ClpXP Proximity Maps and Taking Snapshots of In Situ Interaction Networks. Cell Chem. Biol. 26, 48-59.e7 (2019). doi:10.1016/j.chembiol.2018.10.007

289. Makarov, A.A., Zou, J., Houston, D.R., Spanos, C., Solovyova, A.S., Cardenal-Peralta, C., Rappsilber, J., Schirmer, E.C.: Lamin A molecular compression and sliding as mechanisms behind nucleoskeleton elasticity. Nat. Commun. 10, 3056 (2019). doi:10.1038/s41467-019-11063-6

290. McHugh, T., Zou, J., Volkov, V.A., Bertin, A., Talapatra, S.K., Rappsilber, J., Dogterom, M., Welburn, J.P.I.: The depolymerase activity of MCAK shows a graded response to Aurora B kinase phosphorylation through allosteric regulation. J. Cell Sci. 132, (2019). doi: $10.1242 /$ jcs. 228353

291. Müller, F., Graziadei, A., Rappsilber, J.: Quantitative Photo-crosslinking Mass Spectrometry Revealing Protein Structure Response to Environmental Changes. Anal. Chem. 91, 9041-9048 (2019)

292. Bürmann, F., Lee, B.-G., Than, T., Sinn, L., O’Reilly, F.J., Yatskevich, S., Rappsilber, J., Hu, B., Nasmyth, K., Löwe, J.: A folded conformation of MukBEF and cohesin. Nat. Struct. Mol. Biol. 26, 227-236 (2019)

293. Iacobucci, C., Piotrowski, C., Rehkamp, A., Ihling, C.H., Sinz, A.: The First MSCleavable, Photo-Thiol-Reactive Cross-Linker for Protein Structural Studies. J. Am. Soc. Mass Spectrom. 30, 139-148 (2019). doi:10.1007/s13361-018-1952-8

294. Wittig, S., Haupt, C., Hoffmann, W., Kostmann, S., Pagel, K., Schmidt, C.: Oligomerisation of Synaptobrevin-2 Studied by Native Mass Spectrometry and Chemical Cross-Linking. J. Am. Soc. Mass Spectrom. 30, 149-160 (2019). doi:10.1007/s13361018-2000-4

295. Yu, C., Wang, X., Huszagh, A.S., Viner, R., Novitsky, E., Rychnovsky, S.D., Huang, L.: Probing H2O2-mediated Structural Dynamics of the Human 26S Proteasome Using Quantitative Cross-linking Mass Spectrometry (QXL-MS). Mol. Cell. Proteomics. 18, 954-967 (2019). doi:10.1074/mcp.tir119.001323 
296. Huang, R., Zhu, W., Wu, Y., Chen, J., Yu, J., Jiang, B., Chen, H., Chen, W.: A novel mass spectrometry-cleavable, phosphate-based enrichable and multi-targeting protein crosslinker. Chem. Sci. 10, 6443-6447 (2019). doi:10.1039/c9sc00893d 